\title{
Shapes and Fall Speeds of Freezing and Frozen Raindrops
}

\author{
KALIMUR RAHMAN AND FIRAT Y. TESTIK \\ Civil and Environmental Engineering Department, The University of Texas at San Antonio, San Antonio, Texas
}

(Manuscript received 5 September 2019, in final form 23 February 2020)

\begin{abstract}
This study investigates the shapes and fall speeds of freezing and frozen raindrops through field observations using an instrument called the high-speed optical disdrometer (HOD) that we developed recently. Our field observations showed that while the shapes of all of the observed freezing raindrops and a portion of the frozen raindrops ( $39 \%$ of the frozen raindrops that are larger than $1.0 \mathrm{~mm}$ in volume equivalent diameter $D$ ) resemble the shapes of warm raindrops, majority of frozen raindrops $(61 \%$ of the frozen raindrops with $D>$ $1.0 \mathrm{~mm}$ ) exhibited a distinct feature such as a spicule, bulge, cavity, or aggregation. Field observations of axis ratios (i.e., ratio of the vertical to horizontal chord) and fall speeds were compared with the predictions of available models. Separate empirical axis ratio parameterizations were developed for the freezing and frozen raindrops using the HOD field observations and extensions to an available shape model were also incorporated. For the fall speeds of freezing and frozen raindrops, field observations demonstrated a good agreement with the predictions of the available parameterizations. Frozen raindrops showed a larger scatter of fall speeds around the mean fall speed of a given drop size than those of the freezing raindrops due to the shape variety among the frozen raindrops with the aforementioned distinct features. The drag coefficients for the observed hydrometeors were compared with the predictions of the available drag coefficient models. Separate "drag coefficient-Reynolds number" relationships for freezing and frozen raindrops were developed.
\end{abstract}

\section{Introduction}

In this study, fall speed and shape characteristics of freezing and frozen raindrops were investigated through field observations. These characteristics are crucial for accurate retrieval of freezing and frozen rainfall characteristics using weather radars as well as identification of these precipitation types, which have important applications. For example, freezing rainfall may lead to various dangerous situations such as dangerous driving conditions on slippery roads due to black-ice formation, power outages due to power lines broken by the added ice weight, airflow alteration in the aircraft wings due to the added ice load, which eventually increases drag and alters the aerodynamic lift, damages to the aircraft engines due to break off of the icicle formations (e.g., Symons and Perry 1997; Rauber et al. 2000; Jung et al. 2012). Similarly, aircraft ground-based deicing fluids may have functional issues due to the presence of frozen raindrops (FAA Notice N 8000.309, 2005). Moreover, frozen raindrops at the ground level result from partially frozen drops in the subfreezing layer, which may cause

Corresponding author: Firat Y. Testik, firat.testik@utsa.edu hazardous conditions for aircrafts passing the subfreezing layer (Zerr 1997). Although there are some widely accepted fall speed and axis ratio parameterizations for warm raindrops available in the literature (e.g., Atlas et al. 1973; Beard and Chuang 1987; Andsager et al. 1999), such parameterizations are limited for freezing and frozen raindrops (Khvorostyanov and Curry 2002; Heymsfield and Westbrook 2010). This study aimed to evaluate capabilities of the available parameterizations in predicting the freezing and frozen raindrop characteristics using field observations, implement extensions to the available models, develop new empirical parameterizations, and provide a high-quality dataset with unique observations on these types of precipitation.

Freezing of water drops and melting of the ice particles at different elevations in the atmospheric column is a common process. Drop freezing may occur spontaneously (nucleation without the presence of an ice nucleus, i.e., homogeneous nucleation) or by contacting another substance (solid particle such as dust or ash) that acts as a nucleus for freezing (i.e., heterogeneous nucleation). Crystallization through heterogeneous nucleation may occur in three different ways depending on the initial position of the ice nucleus. An ice nucleus may 
(i) exist inside of the drop (crystallization from inside out), (ii) contact the drop from its outer surface (crystallization from outside in), and (iii) contact the drop from the inner surface of the drop (crystallization from inside out) (Durant and Shaw 2005; Sastry 2005). The latter two types of crystallization through heterogeneous nucleation by contacting the drop are also termed as contact nucleation. Contact nucleation enhances the growth of ice particles (Hobbs and Rangno 1985; Korolev et al. 2004). Depending on the ambient and raindrop temperature, a raindrop freezes in two different ways: (i) freezing starts from the inside core and proceeds outwards through the process of evaporation freezing (e.g., Durant and Shaw 2005; Jung et al. 2012), or (ii) freezing starts from the outer surface, which is the coldest part of the raindrop, and proceeds inwards (e.g., Mason and Maybank 1960; Koenig 1963; Gibson and Stewart 2007). During the freezing process, water expands and the raindrop volume increases. Since water is an incompressible fluid, if the raindrop freezing starts from the outer surface, water pressure may build up within the raindrop. This excess pressure may be released through a relatively weaker part of the frozen outer surface of the raindrop by formation of surface irregularities/deformities such as an ice spicule, bulge, and cavity (Dye and Hobbs 1968; Takahashi 1975, 1976). The surface deformity continues to grow until the pressure is fully released.

Melting of the ice particles that formed at the cloud level occurs when the ice particles fall through a warm atmospheric layer where the temperature is above $0^{\circ} \mathrm{C}$. This layer is called the melting layer. Between the melting layer and the ground level, there may exist an atmospheric layer referred to as the refreezing layer, where the temperature is subfreezing. Depending mainly on the melting and refreezing layer characteristics, warm raindrops and ice particles formed at the cloud level may reach the ground level as freezing or frozen raindrops (Zerr 1997). During the fall through the melting layer, ice particles may melt partially or completely. When it is complete melting, the hydrometeor may remain as a supercooled water drop and reach the ground surface as a freezing raindrop. When it is partial melting, the frozen portion of the hydrometeor acts as an ice nucleus to refreeze and form a frozen raindrop in the refreezing layer or at the lower boundary of the melting layer that will reach the ground surface as a frozen raindrop (Zerr 1997). During the freezing process, supercooled liquid droplets may accrete on the drop surface, and the accreted liquid water on the surface may either freeze immediately or gradually to become the frozen outer surface. In the case of gradual freezing of the accreted liquid water, a portion of the liquid water may remain unfrozen due to the unbalance of energies among latent heat flux of freezing from the inner core, and sensible and latent heat fluxes at the outer surface (Khain and Pinsky 2018). The presence of accreted liquid water on the drop surface may delay the freezing process and the drop may fall as a water-coated frozen drop (Bruning et al. 2007).

Relevant information on the microphysical characteristics of freezing and frozen raindrops documented in the literature is discussed in the following sections. This article is organized as follows. Background information on the fall speed (and drag) and shape of freezing and frozen raindrops are given in section 2 . The field site and data collection methodologies are presented in section 3 . Our findings on the fall speed, drag coefficient, and shape of freezing and frozen raindrops are discussed in section 4 , and conclusions are provided in section 5 .

\section{Fall speeds and shapes}

When a raindrop falls through the atmosphere, drag, buoyancy, and gravitational forces act on it. Considering that the $\operatorname{drag}\left[F_{d}=(1 / 2) C_{d} \rho_{a} A U^{2}\right.$, where $C_{d}$ is drag coefficient, $\rho_{a}$ is air density, $U$ is fall speed, and $A$ is projected area of the drop] and buoyancy $\left(F_{b}=\rho_{a} V g\right.$, where $V$ is drop volume and $g$ is gravitational acceleration) forces act upward and the gravitational force ( $W=\rho_{d} V g$, where $W$ is weight and $\rho_{d}$ is drop density) acts downward, the force balance on the raindrop that is falling at the terminal speed can be expressed as

$$
\frac{1}{2} C_{d} \rho_{a} A U_{t}^{2}+\rho_{a} V g=\rho_{d} V g .
$$

Note that the raindrop fall speed $U$ is replaced by the terminal fall speed $U_{t}$ in Eq. (1). Using Eq. (1), $U_{t}$ can be parameterized as

$$
U_{t}=\sqrt{\frac{2\left(\rho_{d}-\rho_{a}\right) V g}{C_{d} \rho_{a} A}} .
$$

The calculation of terminal fall speed using Eq. (2) requires information on the drag coefficient, which depends on the flow Reynolds number $\left(\operatorname{Re}=U_{t} D \rho_{a} / \mu_{a}\right.$, where $D$ is volume equivalent raindrop diameter and $\mu_{a}$ is dynamic viscosity of air). Gunn and Kinzer (1949) provided the calculated $C_{d}$ values as a function of Re using the experimental measurements of water drops falling at terminal speeds in a controlled laboratory environment. These $C_{d}$ values for water drops, however, do not account for the atmospheric conditions, which may be significantly different than the laboratory conditions. Therefore, one may expect that the drag coefficient 
values for freezing and frozen raindrops may differ from those provided by Gunn and Kinzer.

A functional relationship between $C_{d}$ and $\mathrm{Re}$ for a rigid sphere is provided by Abraham (1970) as

$$
C_{d}=C_{0}\left(1+\frac{\delta_{0}}{\sqrt{\mathrm{Re}}}\right)^{2}
$$

Here $C_{0}$ is the drag coefficient for the potential flow around the sphere and boundary layer assembly, and $\delta_{0}$ is a dimensionless constant. Based upon Abraham's interpretation of the viscous flow around a rigid sphere in terms of the inviscid flow around the sphere and boundary layer assembly, which has a nonspherical shape, Eq. (3) with appropriate $C_{0}$ and $\delta_{0}$ values may be used for hydrometeors with small shape deviations from a sphere. Abraham suggested the $C_{0}$ and $\delta_{0}$ values for rigid spheres as 0.292 and 9.06, respectively, and noted that one may identify these parameters by fitting the experimental data with $\delta_{0}$ being an adjustable parameter in the fit. Later, Böhm (1989) and Heymsfield and Westbrook (2010) proposed the values of $C_{0}$ and $\delta_{0}$ as $C_{0}=0.6$ and $\delta_{0}=5.83$ and $C_{0}=$ 0.35 and $\delta_{0}=8.0$, respectively, for solid hydrometeors. The $C_{0}$ and $\delta_{0}$ values for freezing and frozen raindrops, which exhibit increasing deviations from a spherical shape with increasing size, are not available in the literature. In section $4 \mathrm{a}, C_{0}$ and $\delta_{0}$ values for freezing and frozen raindrops are identified using our field measurements.

Equation (2) being an implicit equation due to the dependency of $C_{d}$ on $U_{t}$, typically a relationship between the Best number $\left(X=C_{d} \operatorname{Re}^{2}\right)$ and Reynolds number is utilized for terminal fall speed calculations. The Best number $X$, which is a function of the physical properties of the drop and the ambient fluid, can be expressed as follows:

$$
X=C_{d} \operatorname{Re}^{2}=C_{d} \frac{U_{t}^{2} D^{2}}{v_{a}^{2}}=\frac{2\left(\rho_{d}-\rho_{a}\right) V g D^{2}}{\rho_{a} A v_{a}^{2}} .
$$

Here, $v_{a}$ is the kinematic viscosity of air. Once a unique relationship between $X$ and Re is established, Re can be computed using the value of $X$, which can be calculated from the known physical properties of the drop and ambient conditions using Eq. (4). The terminal fall speed of a drop can then be estimated using the following equation without use of the drag coefficient information:

$$
U_{t}=\frac{\mu_{a} \operatorname{Re}}{\rho_{a} D}
$$

Beard (1976) formulated $X$-Re relationships for three different drop diameter ranges: (i) $0.5-19 \mu \mathrm{m}$, (ii) $19 \mu \mathrm{m}-$ $1.07 \mathrm{~mm}$, and (iii) $1.07-7 \mathrm{~mm}$. Raindrops fall in size ranges (ii) and (iii), and Beard's terminal fall speed parameterizations for these size ranges are given in the appendix. Khvorostyanov and Curry $(2002,2005)$ established a continuous parameterization for the terminal fall speed using a power law formulation for the entire size range of hydrometeors. The form of the power law formulation for the $X$-Re relationship is as follows:

$$
\operatorname{Re}=a_{\mathrm{Re}} X^{b_{\mathrm{Re}}} .
$$

The coefficients for the $X$-Re relationship in Eq. (6) are provided by Khvorostyanov and Curry as follows:

$b_{\mathrm{Re}}(X)=\frac{1}{2} c_{1} X^{1 / 2}\left[\left(1+c_{1} X^{1 / 2}\right)^{1 / 2}-1\right]^{-1}\left(1+c_{1} X^{1 / 2}\right)^{-1 / 2}$,

$a_{\mathrm{Re}}(X)=\frac{\frac{\delta_{0}^{2}}{4}\left[\left(1+c_{1} X^{1 / 2}\right)^{1 / 2}-1\right]^{2}}{X^{b_{\mathrm{Re}}(X)}}$.

Here, $c_{1}=4 /\left(\delta_{0}^{2} \sqrt{C_{0}}\right)$ and its value is 0.0902 for the suggested $\delta_{0}$ and $C_{0}$ values of 9.06 and 0.29 , respectively, by Abraham (1970). Combining Eqs. (4) and (6) to derive $C_{d}$ in terms of $a_{\mathrm{Re}}, b_{\mathrm{Re}}$, and $X$, and then incorporating this $C_{d}$ expression into Eq. (2), the terminal fall speed of the hydrometeors can be parameterized as follows (Khvorostyanov and Curry 2002):

$$
U_{t}=a_{\mathrm{Re}} v_{a}^{1-2 b_{\mathrm{Re}}}\left[\frac{4}{3} g \alpha\left(\frac{\rho_{d}}{\rho_{a}}-1\right)\right]^{b_{\mathrm{Re}}} D^{3 b_{\mathrm{Re}}-1} .
$$

Here, $\alpha$ is the axis ratio relationship given in Eq. (10) that was developed by Khvorostyanov and Curry (2002) for nonspherical drops by considering drop oblateness.

$$
\alpha=\exp \left(-\frac{D}{\lambda}\right)+\left[1-\exp \left(-\frac{D}{\lambda}\right)\right]\left[\frac{1}{1+(D / \lambda)}\right] .
$$

Here, $\lambda$ is used as $4.7 \mathrm{~mm}$ by Khvorostyanov and Curry (2002).

Heymsfield and Westbrook (2010) utilized the analytical concept implemented by Böhm (1989), Mitchell (1996), and Khvorostyanov and Curry $(2002,2005)$ to derive an $X-\operatorname{Re}$ relationship to estimate the terminal fall speed of frozen hydrometeors. However, Heymsfield and Westbrook's model uses the modified Best number $X^{*}$, which is defined as follows:

$$
X^{*}=C_{d}^{*} \operatorname{Re}^{2}=\frac{\rho_{a}}{\mu_{a}^{2}} \frac{8 m g}{\pi A_{r}^{0.5}},
$$

where $C_{d}^{*}$ is the modified drag coefficient defined in Eq. (12), $A_{r}$ is the area ratio (ratio of the hydrometeor's 
projected area to the area of a circumscribing circle normal to the direction of fall), and $m$ is the mass of the hydrometeor.

$$
C_{d}^{*}=C_{d} A_{r}^{0.5} .
$$

Following Böhm (1989) and replacing $X$ with $X^{*}$ as Heymsfield and Westbrook (2010) implemented, the Re relationship given in Eq. (13) can be derived:

$$
\operatorname{Re}=\frac{\delta_{0}^{2}}{4}\left[\left(1+\frac{4 \sqrt{X^{*}}}{\delta_{0}^{2} \sqrt{C_{0}}}\right)^{1 / 2}-1\right]^{2}
$$

Based on the laboratory data, Heymsfield and Westbrook suggested that $C_{0}=0.35$ and $\delta_{0}=8.0$. The terminal fall speeds of the hydrometeors can then be calculated using Eq. (5).

The shape characteristics of freezing and frozen raindrops are crucial in determining reflectivity from dual polarization radar during such precipitation events. The shape observations of freezing and frozen raindrops were conducted previously through laboratory experiments as well as from in situ observations (Dye and Hobbs 1968; Visagie 1969; Takahashi 1975; Gibson and Stewart 2007). Freezing raindrops typically hold similar shapes to those of warm raindrops. However, the shape of frozen raindrops varies considerably depending on the mechanism of their formation and the surrounding atmospheric conditions.

Frozen hydrometeors may exhibit shapes with surface deformities including bulges, spicules, cavities/fractures in addition to the spherical and oblate shapes that are similar to those of warm raindrops. Spicule formation on the frozen raindrop surface has long been studied and well documented in the literature (e.g., Blanchard 1951, 1957; Hallett 1960; Mason and Maybank 1960; Pitter and Pruppacher 1973; Takahashi 1975, 1976; Hogan 1985; Stewart and Crawford 1995; Knight 1998; Hill et al. 2004; Libbrecht and Lui 2004; Gibson and Stewart 2007; Gibson et al. 2009). To form an ice spicule on the surface of a frozen raindrop, freezing needs to begin at the outer raindrop surface by forming a thin ice shell that surrounds the water in the core. Initially, the ice shell grows inward which builds pressure within the drop. This excess pressure due to the volume expansion is released by expelling water out of a crack or unfrozen hole at the drop surface. The expelled water then freezes to form an ice spicule (Takahashi 1975; Gibson and Stewart 2007). The ice spicule continues to expand until the excess pressure is fully released. This process of forming ice spicule is known as the Bally-Dorsey model proposed by Bally (1935) and Dorsey (1938). During the freezing process, fragmentation of the ice spicule may occur
(Mason and Maybank 1960; Braham 1964; Kikuchi et al. 2013). Bulges on the frozen raindrop surfaces have lengths that are typically less than one-fourth of the drop diameter (Gibson and Stewart 2007). These bulges may form as the raindrop outer surface freezes as an ice shell, which thickens during the freezing process and builds up pressure within the drop. This excess pressure may eventually be released either through the bulging shape deformation (Takahashi 1975) or pushing water through one or multiple holes on the ice shell, which then freezes on the drop surface and forms a bulge (Mason and Maybank 1960; Visagie 1969). Frozen raindrops with fractures/cavities on the surface were observed by Brooks (1920), Blanchard (1957), Kolomeychuk et al. (1975), Takahashi (1975, 1976), and Stewart and Crawford (1995). Cavity formation on the frozen raindrop surface is attributed to the weakness of the ice shell (Takahashi 1976). Frozen raindrops may form over several freezingexpansion cycles. As such, pressure may build up and release cyclically, and a cavity may form on the raindrop surface once the excess pressure is released and a negative pressure may prevail on a part of the raindrop surface. In addition to these surface deformities, collision of frozen raindrops may result in coalescence. However, coalesced frozen raindrops differ significantly from the coalesced warm raindrops that were recently documented by Testik and Rahman (2017) using in situ high-speed optical disdrometer (HOD) observations. A coalesced frozen raindrop, also referred to as an "aggregate," is composed of parent drops that are intact after the collision and are connected with a distinct neck for the rest of the fall through the atmospheric column. In contrary, the shapes of the coalesced warm raindrops do not exhibit a memory of the collision. Instead, after a period of adjustment through oscillations, a larger raindrop with the total volume of the parent drops and an equilibrium shape forms. Frozen raindrops may not exhibit shape deformities. One possibility for the absence of shape deformities is that the outer surface of the frozen raindrops may undergo melting by the flow of latent heat from freezing of the inner core while the ambient temperature is subfreezing. This process and accretion of liquid water on the drop surface may lead to water coated frozen raindrops noted earlier (Bruning et al. 2007; Phillips et al. 2015; Khain and Pinsky 2018), which may be responsible for the frozen raindrop observations without shape deformities.

\section{Field site and data collection}

In this study, freezing and frozen precipitation events were observed at our field site located in the Simpson Agricultural field near Pendleton, South Carolina. The coordinates and elevation of this outdoor rainfall research 
TABLE 1. Conditions during the freezing and frozen precipitation events.

\begin{tabular}{cccccc}
\hline \hline Precipitation type & Date & Start time $(\mathrm{UTC})$ & End time $(\mathrm{UTC})$ & Temperature $\left({ }^{\circ} \mathrm{C}\right)$ & Relative humidity $(\%)$ \\
\hline Freezing rain & 16 Feb 2015 & 1736 & 2121 & -1.8 to 2.7 & $31-84$ \\
& & 2226 & 2315 & -1.5 to -1.3 & $88-91$ \\
\multirow{2}{*}{ Frozen rain } & 17 Feb 2015 & 0359 & 0558 & -0.2 to 0.0 & $95-96$ \\
\hline
\end{tabular}

laboratory are $34^{\circ} 37^{\prime} 26.48^{\prime \prime} \mathrm{N}, 82^{\circ} 43^{\prime} 58.2^{\prime \prime} \mathrm{W}$, and $255 \mathrm{~m}$ MSL, respectively. The field site is situated within a flat agricultural land that is free of big trees and any other obstructions that could disturb the fall of hydrometeors. There are two National Oceanic and Atmospheric Administration's National Weather Service (NOAA/NWS) weather stations in the close proximity of this field site that are located at: 1) Clemson Oconee County regional airport, and 2) Anderson County regional airport. Both of the weather stations are within $10 \mathrm{mi}$ of the field site. The NOAA NWS weather stations at both Anderson and Oconee County regional airports are equipped with Automated Surface Observing Systems (ASOS). Precipitation identification sensors [Light Emitting Diode Weather Identifier (LEDWI)] and freezing rain sensors (by Rosemount Aerospace, Model 0872C3) are available at both of these stations to discern between liquid precipitation and frozen precipitation, and to identify the presence of freezing rainfall automatically. Details of the ASOS and embedded sensors can be found in NOAA et al. (1998). Local weather conditions from the NOAA website (i.e., hourly observations of local climatological data) for these two weather stations were in agreement with our field observations for the precipitation events considered in this study. The freezing and frozen precipitation events were captured on 16 and 17 February 2015. Table 1 lists the time information and environmental conditions for the precipitation events. A freezing precipitation event is defined as the uninterrupted precipitation of freezing raindrops that are in liquid state during the fall at a temperature $\left(<0^{\circ} \mathrm{C}\right)$ that become frozen upon contact with the ground surface. On the other hand, a frozen precipitation event is defined as the uninterrupted precipitation of frozen raindrops that are in solid state during the fall at a temperature $\left(<0^{\circ} \mathrm{C}\right)$. The frozen raindrops remain frozen upon contact with the ground surface. An observer can identify a freezing or frozen precipitation event by visually identifying the ground surface condition, measuring the ambient temperature, and checking the state of the falling raindrops.

Field observations of the hydrometeors were obtained using a state-of-the-technology instrument called as the HOD, which was developed by Testik and Rahman (2016). This new technology and its capabilities are documented in Testik and Rahman (2016) in detail. Briefly, the
HOD can monitor both liquid and frozen hydrometeors such as warm, freezing, and frozen raindrops as well as snowflakes and hail. It includes of a high-speed camera that points at an LED light and captures the side-view (i.e., normal to the direction of gravitational acceleration) silhouettes of hydrometeors at a rate of 1000 frames per second. The LED light facilitates a nonfluctuating light source throughout the observations and a diffuser was used to form a uniform background light for captured images. The HOD also includes a sensing unit to capture images only when hydrometeors are present within the HOD's virtual measurement volume of $25670 \mathrm{~mm}^{3}$ around the camera's focal plane. The HOD collects batch-wise hydrometeor images, a batch being 3 gigabytes of highquality images for a number of hydrometeors. In this study, images for a total of 1014 freezing and 1976 frozen hydrometeors that are larger than $0.5 \mathrm{~mm}$ were collected. For each of the hydrometeors, a predefined number of sequential images (10 images in this study) are captured. After collection of image batches, the HOD software identifies the hydrometeor boundaries and calculates the geometric and dynamic characteristics (e.g., hydrometeor volume equivalent diameter, axis ratio, and fall velocity) using digital image processing techniques and algorithms. Since the same hydrometeor is observed multiple times in the sequential images, different characteristics for a given hydrometeor are calculated at multiple instances and can be averaged over the instantaneous measurements, if preferred. For example, averaging of the fall speed may be desired to reduce oscillation-induced scatter of raindrop fall speeds. In this study, the HOD was installed at an elevation of $2 \mathrm{~m}$ above the ground level. Figure 1 shows the field site, the HOD, and conditions during the field experiments.

As listed in Table 1, freezing and frozen rainfall events were back to back. To delineate these two different type of events and assign the HOD image batches to freezing and frozen rainfall accurately, we primarily relied on the information from the following three different sources: (i) human observations during the field experiment; (ii) hourly weather reports from the NOAA/NWS weather stations at the Oconee and Anderson County regional airports, which are within $10 \mathrm{mi}$ of the field site; and (iii) visually going through the HOD image batches. For (i), we noted the precipitation type that we observed at 

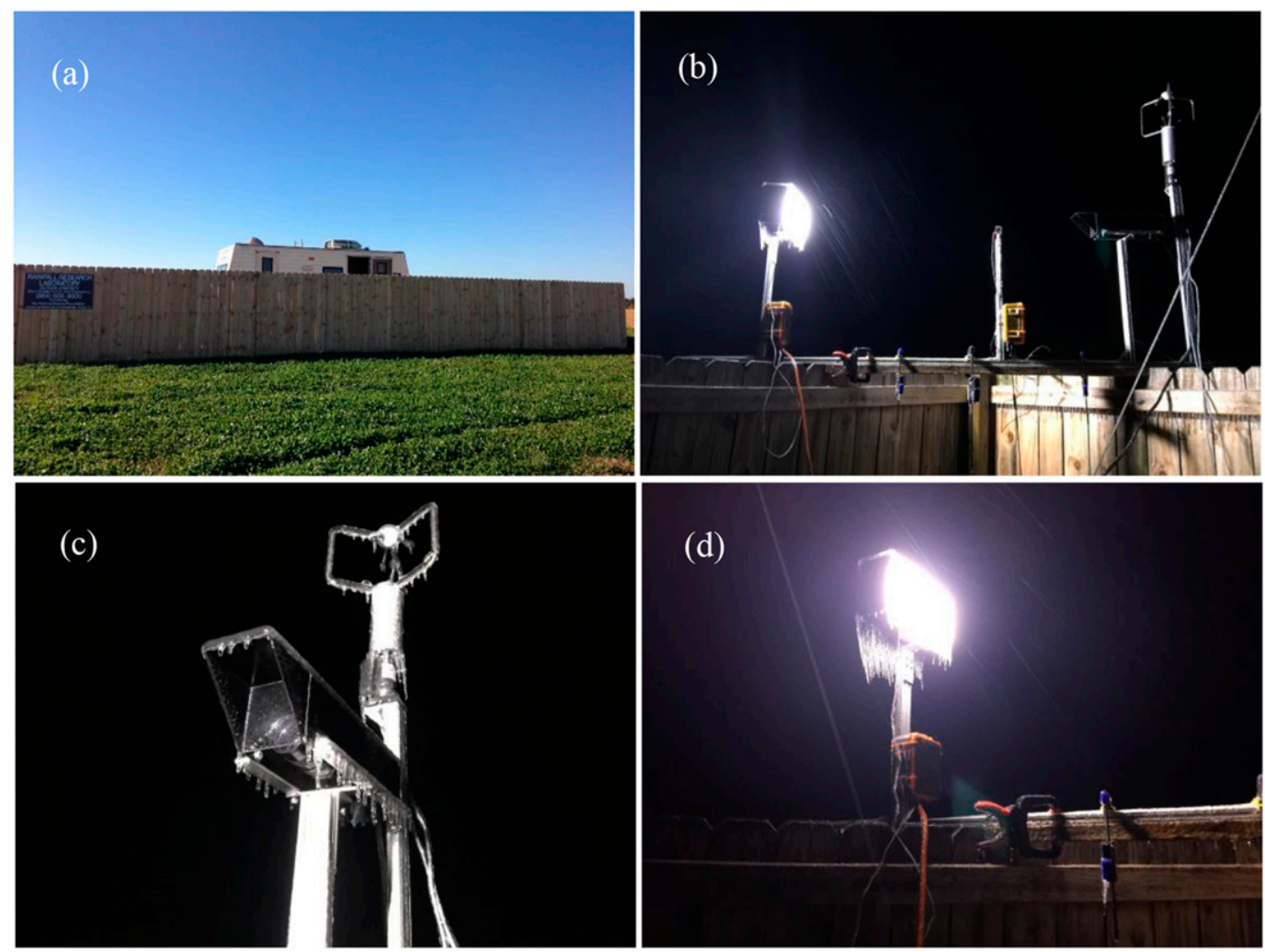

FIG. 1. Photographs showing (a) the field site, (b) the HOD installed over the wooden fences at $2 \mathrm{~m}$ above the ground surface, (c) the icicle formations on the HOD's high-speed camera enclosure and the ultrasonic anemometer, and (d) the light source during the freezing rainfall events.

the field site at every $5 \mathrm{~min}$ of the field experiment. For (ii), reports from the NOAA NWS weather stations were hourly and were mainly used to support our frequent visual observations in (i). For (iii), surface deformities, which are characteristics of frozen raindrops, were clearly identifiable in the HOD images (see Fig. 6) and provided an additional mean to differentiate the type of observed rainfall events. Despite all our best efforts, given the nature of these precipitation events, it is possible that freezing raindrops may exist in the frozen raindrop batches and vice versa. However, we anticipate that only a small number of potential outliers may exist in a given batch, and we do not expect significant effects of such potential outliers on the presented results.

\section{Results and discussion}

Our field observations and findings on the fall speeds and shapes of freezing and frozen raindrops are presented in the following two subsections.

\section{a. Fall speeds of freezing and frozen raindrops}

As discussed in section 2, knowledge of the $C_{d}-\mathrm{Re}$ relationship is essential to parameterize fall speeds of hydrometeors. The mathematical form of Abraham (1970) $C_{d}-$ Re relationship [see Eq. (3)] involves two constants, $C_{0}$ and $\delta_{0}$. Using our field observations, we determined the values of these constants for freezing and frozen raindrops separately. For this purpose, the drag coefficients of the observed freezing and frozen raindrops were calculated using the balance of forces acting on the raindrops as described in section 2 [see Eqs. (1) and (2)]. Rearranging Eq. (2) for $C_{d}$ and calculating raindrop volume as $V=(4 / 3) \pi(D / 2)^{3}$ yield

$$
C_{d}=\frac{\frac{4}{3} \pi\left(\frac{D}{2}\right)^{3}\left(\rho_{d}-\rho_{a}\right) g}{\frac{1}{2} A \rho_{a} U_{t}^{2}} .
$$

The density of the freezing and frozen raindrops $\rho_{d}$ was estimated following Holten et al. (2014) and Jones (1998), respectively, using the ambient temperature measurements at the field site. The density of moist air $\rho_{a}$ was used as $1.289563 \mathrm{~kg} \mathrm{~m}^{-3}$ at sea level condition in all of our calculations. For $C_{d}$ calculations using Eq. (14), measured fall speeds of the freezing and frozen raindrops were used with the assumption of measured speeds being 

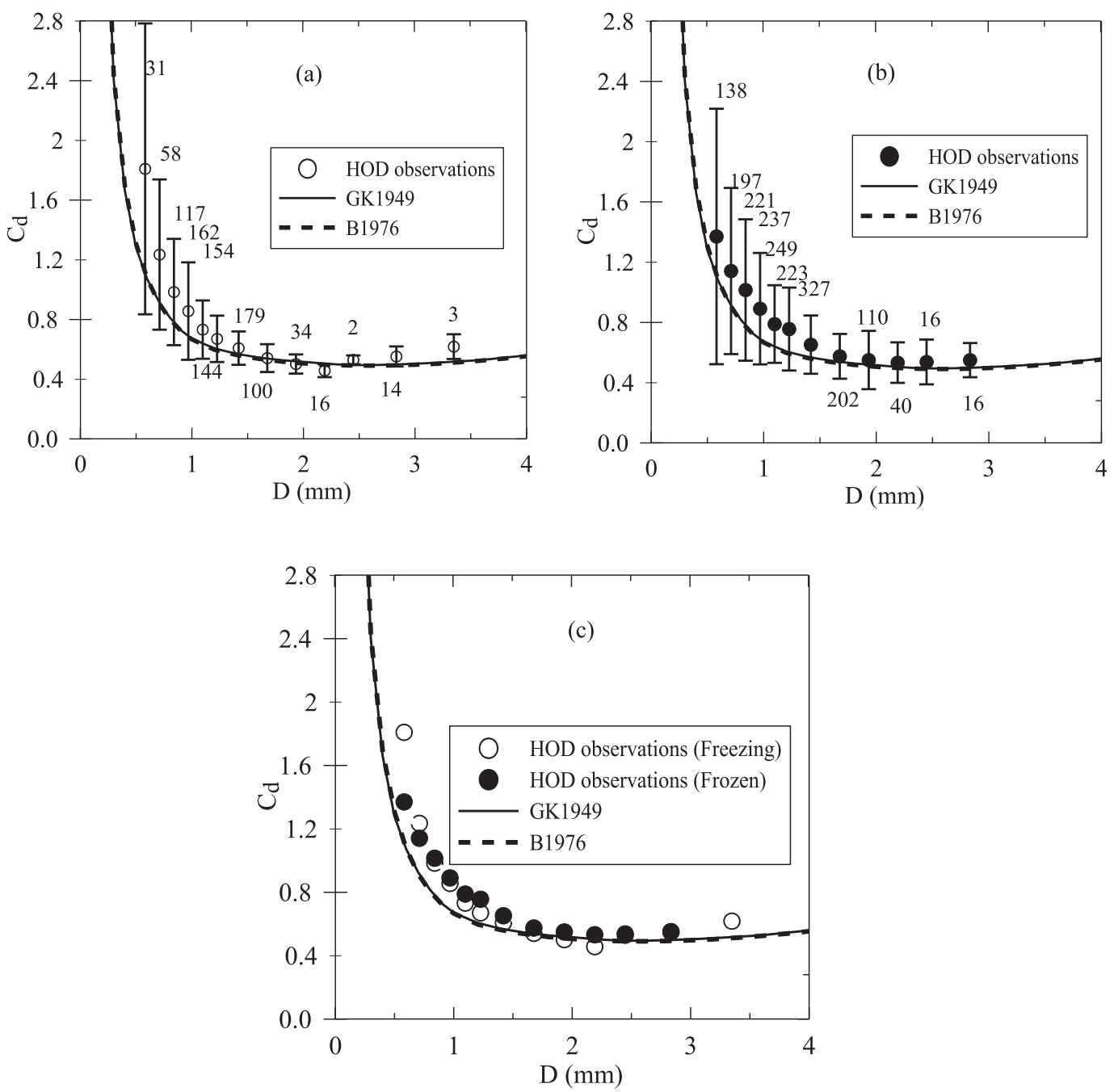

FIG. 2. Comparisons of the drag coefficients of the observed freezing raindrops (open circles), frozen raindrops (solid circles), warm raindrops from Gunn and Kinzer (1949) (GK1949, solid line) and from Beard (1976) at sea level (B1976, dashed line) in the legend: (a) freezing and warm raindrops; (b) frozen and warm raindrops; (c) freezing, frozen, and warm raindrops. For each diameter bin, standard deviation of drag coefficients from the average drag coefficient of the bin (vertical bars) and number of drops are shown in (a) and (b).

terminal, and the projected area of the raindrops was calculated as $A=\pi(D / 2)^{2}$ with the assumption of raindrops having a circular cross-sectional area defined in terms of the volume equivalent diameter. It is important to note that the HOD images provide information on the side-view cross sections of the hydrometeors and do not provide information on the hydrometeor cross sections that are normal to the direction of gravitational acceleration. Information on the three-dimensional shapes of the hydrometeors may be typically desirable, for example, to study and simulate hydrometeor scattering properties for active and passive remote sensing. Nevertheless, the two-dimensional HOD images provide sufficient information on the hydrometeor shapes for calculating the volume equivalent diameters of freezing and frozen raindrops. Calculations of the volume equivalent diameter from such two-dimensional images necessitate the assumption of axisymmetric hydrometeor shapes around an axis along the direction of gravitational acceleration. This assumption may induce errors in calculated volume equivalent diameters for hydrometeors with shape deformities. However, given that the diameter is calculated as the cubic root of the hydrometeor volume (see Testik and Rahman 2016), such errors are rather small for both freezing and frozen raindrops with and without deformities, and the implications of these errors are limited in the drag coefficient and fall speed calculations.

Figure 2 presents the calculated drag coefficients of the observed freezing and frozen raindrops. In presenting the HOD observations in this figure (and later in 

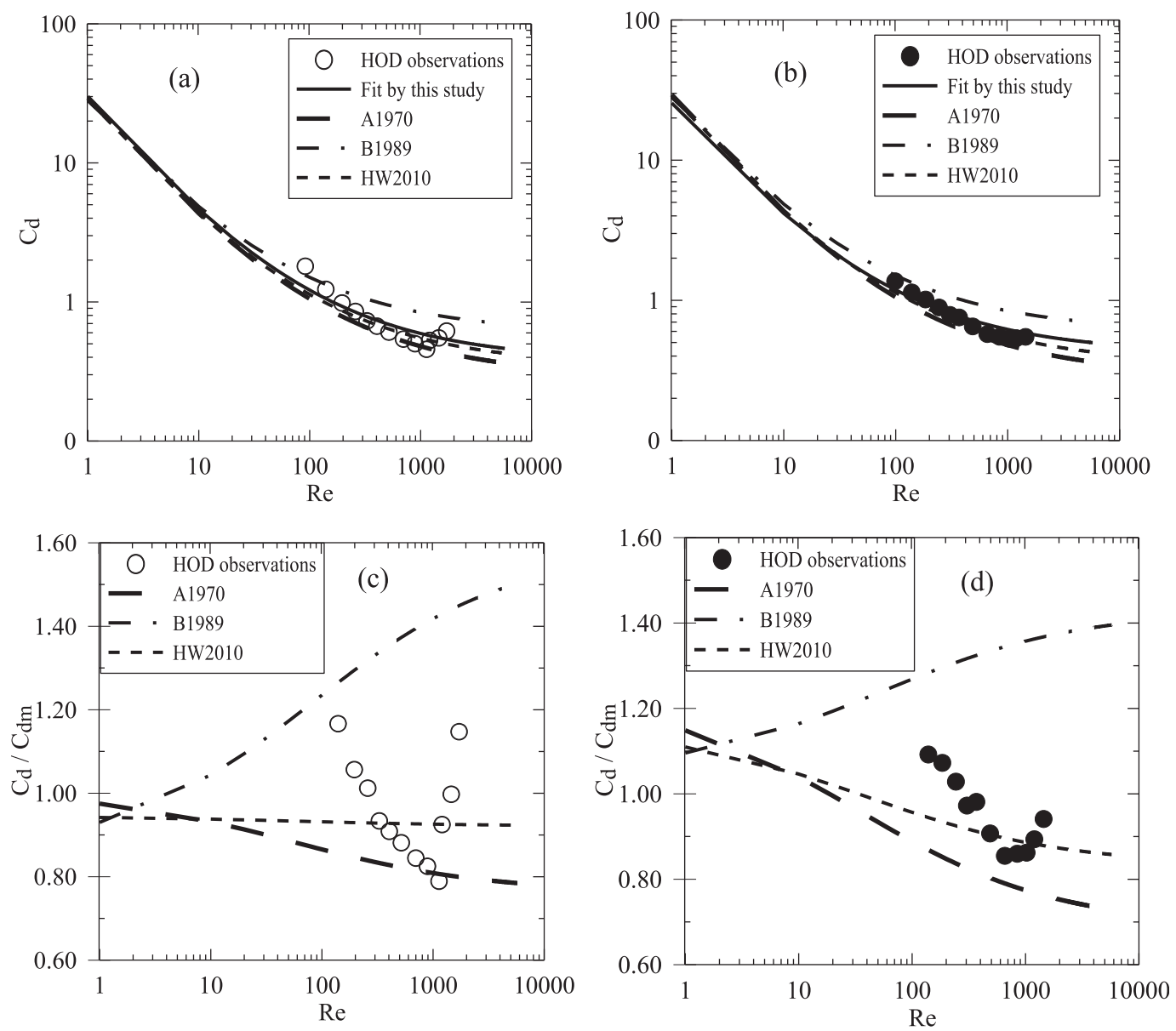

FIG. 3. Drag coefficient as a function of the Reynolds number for the observed (a) freezing (open circles) and (b) frozen (solid circles) raindrops. Observations are compared with the predictions of the relationships by Abraham (1970) (A1970, long dashed line), Böhm (1989) (B1989, dash-dot line), Heymsfield and Westbrook (2010) (HW2010, dashed line), and the empirical fits developed in this study (fit by this study, solid line). Ratios of the drag coefficients by HOD observations, and A1970, B1989, and HW2010 predictions to the predicted drag coefficients by the fit lines of this study $\left(C_{d} / C_{\mathrm{dm}}\right)$ are shown as a function of Re for (c) freezing and (d) frozen raindrops.

Figs. 3, 4, and 11), Parsivel disdrometer's bin sizes for the volume equivalent drop diameters (see NASA 2011) were adopted. This was to be consistent with the large body of literature that utilizes precipitation measurements by Parsivel disdrometers (e.g., Löffler-Mang and Joss 2000; Tapiador et al. 2010; Jaffrain et al. 2011; Tokay et al. 2014; Raupach and Berne 2015; AnguloMartínez et al. 2018). As can be seen from the figure, drag coefficients of frozen raindrops have more scattering from the mean values than those of freezing raindrops. This is attributed due to the shape varieties of frozen raindrops that is discussed in the next subsection. It is also evident that drag coefficients of both freezing and frozen raindrops of $D<1 \mathrm{~mm}$ have larger deviations from the mean values than for those of $D>1 \mathrm{~mm}$. This was because fall speed scattering, although present for all of the observed freezing and frozen raindrop sizes, induce larger drag coefficient deviations for the smaller raindrops. Figure 2 also shows that, for a given size, the drag coefficients of freezing and frozen raindrops are larger than those of warm raindrops.

To determine the $C_{0}$ and $\delta_{0}$ values that are for the freezing and frozen raindrops, the functional form of Eq. (3) with the calculated Re values is fitted to the experimentally obtained $C_{d}$ values from Eq. (14). The $C_{0}$ and $\delta_{0}$ values that give the best fit were determined using the Pearson's correlation coefficient $r$ that is defined in Eq. (15). This analysis led to $C_{0}$ and $\delta_{0}$ values for the observed freezing raindrops as 0.38 and 7.9 , respectively, and for the observed frozen raindrops as 0.42 and 6.8 , respectively. Pearson's correlation coefficient values for the fits were 0.98 for the freezing raindrops and 0.99 

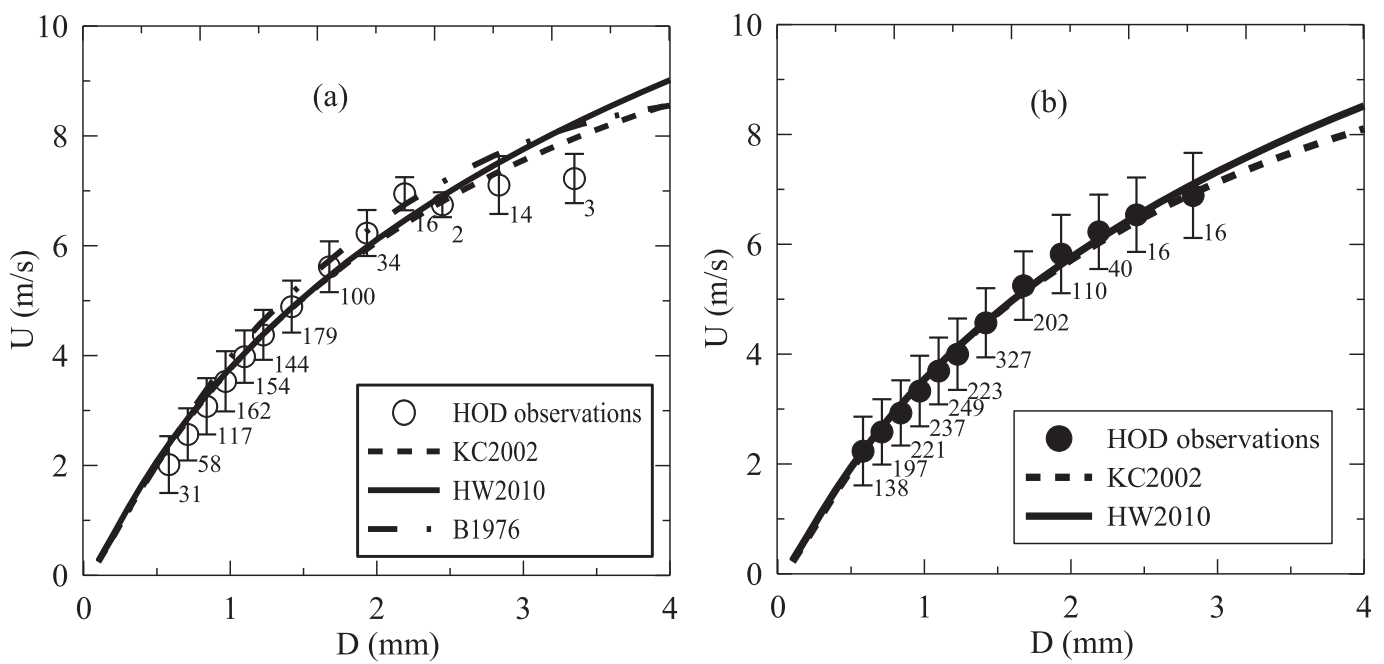

FIG. 4. Average fall speeds of (a) freezing (open circles) and (b) frozen raindrops (solid circles) observed during the field experiments as a function of the drop diameter. For each diameter bin, standard deviation of fall speeds from the average fall speed of the bin (vertical bars) and number of drops are shown. Fall speed predictions of models by Heymsfield and Westbrook (2010) (HW2010, solid line), Beard (1976) (B1976, dash-dot line), and Khvorostyanov and Curry (2002) (KC2002, dashed line) are provided in the figure.

for the frozen raindrops. Note that in fitting $C_{d}-\operatorname{Re}$ for freezing raindrops, the 2.45- and 3.35-mm-diameter bins were omitted as those bins contain only two and three freezing raindrops, respectively:

$$
r=\frac{N\left(\sum C_{d f} C_{d m}\right)-\left(\sum C_{d f}\right)\left(\sum C_{d m}\right)}{\sqrt{\left\{\left[N \sum C_{d f}^{2}-\left(\sum C_{d f}\right)^{2}\right]\left[N \sum C_{d m}^{2}-\left(\sum C_{d m}\right)^{2}\right]\right\}}} .
$$

In Eq. (15), $N$ is the number of observations used in computing the correlation coefficient, $C_{d f}$ is the average drag coefficient for each diameter bin obtained from the field measurements, and $C_{d m}$ is the predicted drag coefficient using Eq. (3) with $C_{0}=0.38$ and $\delta_{0}=7.9$ for freezing and $C_{0}=0.42$ and $\delta_{0}=6.8$ for frozen raindrops. Figure 3 presents the $C_{d}$ and Re values for the observed freezing and frozen raindrops with the best-fit lines. In this figure, predictions of the relationships by Abraham (1970), Böhm (1989), and Heymsfield and Westbrook (2010) are also presented for comparison purposes. To show the differences in this comparison more clearly, ratios of the drag coefficients (field observed in this study and predicted by the relationships of Abraham, Böhm, and Heymsfield and Westbrook) to the predicted drag coefficients by the fit lines of this study $\left(C_{d} / C_{d m}\right)$ are individually shown in Figs. $3 \mathrm{c}$ and $3 \mathrm{~d}$ for freezing and frozen raindrops, respectively. As can be seen in the figure, field observed values for both freezing and frozen raindrops were enveloped by the predictions of Abraham (1970) and Böhm (1989), and the predictions of Heymsfield and Westbrook (2010) were in closer agreement with the observations, especially more so for the frozen raindrops.

Since standard deviations shown in Figs. 2 and 4 (and later in Fig. 11) extend over a range that encompasses freezing, frozen, and warm raindrop populations, we tested the statistical significance of the differences between the freezing and frozen raindrop populations. For this purpose, we performed two-sample $t$ test with unequal variances and tested for equal means of freezing and frozen raindrop fall speed populations for each of the bin sizes for the volume equivalent drop diameters. In the two-sample $t$ test, $t$ value is calculated as

$$
t=\frac{U_{\text {freezing }}-U_{\text {frozen }}}{\sqrt{\frac{\mathrm{SD}_{\text {freezing }}^{2}}{n_{\text {freezing }}}+\frac{\mathrm{SD}_{\text {frozen }}^{2}}{n_{\text {frozen }}}} .}
$$

In Eq. (16), $U_{\text {freezing }}$ and $U_{\text {frozen }}$ are the average fall speeds of freezing and frozen raindrops for each diameter bin obtained from the field measurements. $\mathrm{SD}_{\text {freezing }}$ and $\mathrm{SD}_{\text {frozen }}$ are the standard deviations of fall speeds of freezing and frozen raindrops within a diameter bin, $n_{\text {freezing }}$ and $n_{\text {frozen }}$ are the number of freezing and frozen raindrops within the bin. In this analysis, significance level of 0.05 is used. The $p$ values are then compared with the significance level of 0.05 . Results of the two-sample $t$ test between the freezing and frozen raindrops for each of the diameter bin size are shown in Table 2. It can be inferred from these results that the means of freezing and frozen raindrop fall speed 
TABLE 2. Results of two-sample $t$ test for equality of means of fall speeds for freezing and frozen raindrops for each diameter bin considered.

\begin{tabular}{crcc}
\hline \hline$D$ range $(\mathrm{mm})$ & $t$ value & Degrees of freedom & $p$ value \\
\hline $0.516-0.645$ & -2.04 & 51 & 0.046 \\
$0.645-0.774$ & -0.25 & 114 & 0.799 \\
$0.774-0.903$ & 2.37 & 268 & 0.018 \\
$0.903-1.032$ & 3.38 & 377 & 0.001 \\
$1.032-1.161$ & 5.29 & 379 & 0.000 \\
$1.161-1.290$ & 6.55 & 362 & 0.000 \\
$1.290-1.547$ & 6.47 & 456 & 0.000 \\
$1.547-1.804$ & 5.80 & 255 & 0.000 \\
$1.804-2.061$ & 4.12 & 95 & 0.000 \\
$2.061-2.318$ & 5.49 & 53 & 0.000 \\
$2.318-2.575$ & 0.90 & 4 & 0.421 \\
$2.575-3.090$ & 0.91 & 26 & 0.374 \\
\hline
\end{tabular}

populations are different for all of the $D$ ranges but $0.645-0.774,2.318-2.575$, and $2.575-3.090 \mathrm{~mm}$. As can be seen in Table 2, the largest two $D$ ranges (i.e., 2.318-2.575 and $2.575-3.090 \mathrm{~mm}$ ), which do not have statistically significant differences in the means of freezing and frozen raindrop fall speed populations, have relatively small degrees of freedom values, a quantity that is related to the sample size. The large $p$ values in the smallest two $D$ ranges (i.e., $0.516-0.645$ and $0.645-0.774 \mathrm{~mm}$ ) may be a consequence of increased measurement uncertainties for smaller drop sizes. For the cases with different means of fall speed populations, means of freezing raindrop fall speeds are larger than the means frozen raindrop fall speeds.

Figure 4 presents the HOD measurements for the fall speed as a function of the volume equivalent diameter for the freezing and frozen raindrops. As can be seen from this figure, dependencies of both freezing and frozen raindrop fall velocities on the diameter were similar to that of warm raindrops. In this figure, measured freezing and frozen raindrop fall velocities were compared with the predictions of three different fall speed parameterizations that are by Beard (1976), Khvorostyanov and Curry (2002, 2005), and Heymsfield and Westbrook (2010). Among these parameterizations, Beard's parameterization is only for the liquid raindrops (hence only used for comparisons with freezing raindrops), and the other two parameterizations are for both solid and liquid hydrometeors. These comparisons for freezing raindrops indicate that while predictions from all three parameterizations match well with the observed fall velocities for the entire drop size range observed, the match was closer with the Beard's predictions than others for diameter bins up to $2.19 \mathrm{~mm}$. Beyond this bin size (i.e., the last three bin sizes in Fig. 4a), the observations for freezing raindrops show increasing deviations from the predictions. These deviations are likely due to the small number of observations for those bins (see the number of observations noted next to the symbols in Fig. 4), and the morphodynamic disturbances experienced by those larger drops were not averaged out due to the small sample sizes for those bins. For example, the largest size bin in Fig. 4a includes only three freezing raindrops, and two of these drops were oscillating and the third one was canted. Raindrop oscillations and canting may result in changes in the pressure field around the drop and the drag coefficient, hence in the fall speeds. Testik et al. (2006) presented an oscillating raindrop of approximately $2 \mathrm{~mm}$ in diameter that falls nearly $10 \%$ slower than the predicted terminal speeds for that size raindrops (see Fig. 4 of Testik et al.). For the case of frozen raindrops, Fig. 4b indicates that the observed fall speeds match closely with the fall speed predictions of both Khvorostyanov and Curry (2002, 2005) model and Heymsfield and Westbrook (2010) model for the entire size range. However, standard deviations of the observed fall speeds, which are shown as the vertical bars in Fig. 4, indicate that frozen raindrops of a given bin exhibit larger variations in fall speeds than those of freezing raindrops. This observation can be explained by the larger variety of frozen raindrop shapes than the freezing raindrop shapes as discussed in the next subsection.

Uncertainties associated with the observed fall speeds of freezing and frozen raindrops are investigated using the quantile regressions for the conditional quantiles. This uncertainty estimation technique provides probability distribution of the fall speeds of freezing and frozen raindrops without assumptions for the residual distribution of fall speeds (i.e., difference between observed and fitted fall speeds). Moreover, this technique is suitable for the response variables that do not follow the Gaussian distribution such as precipitation and wind velocity (Friederichs and Hense 2007). For the quantile regression analysis, we used the package "quantreg" in statistical software R. In Fig. 5, scatterplots of fall speeds and quantile functions for the quantiles $0.05,0.5$, and 0.95 are shown. As can be seen in this figure, the fall speed uncertainties are higher in frozen raindrops as compared to freezing raindrops. Higher uncertainties for frozen raindrop fall speeds are related to the larger variations of the frozen raindrop shapes due to shape deformities. It should be noted that quantile regression lines for the quantiles 0.5 and 0.95 overestimated the measured fall speeds of freezing and frozen raindrops for the drop sizes between 2.6 and $3.2 \mathrm{~mm}$. This is because, for this size range, only 14 freezing and 14 frozen raindrops were observed during the field experiments. As sufficient data are required for the conditional quantiles, this technique could not be 

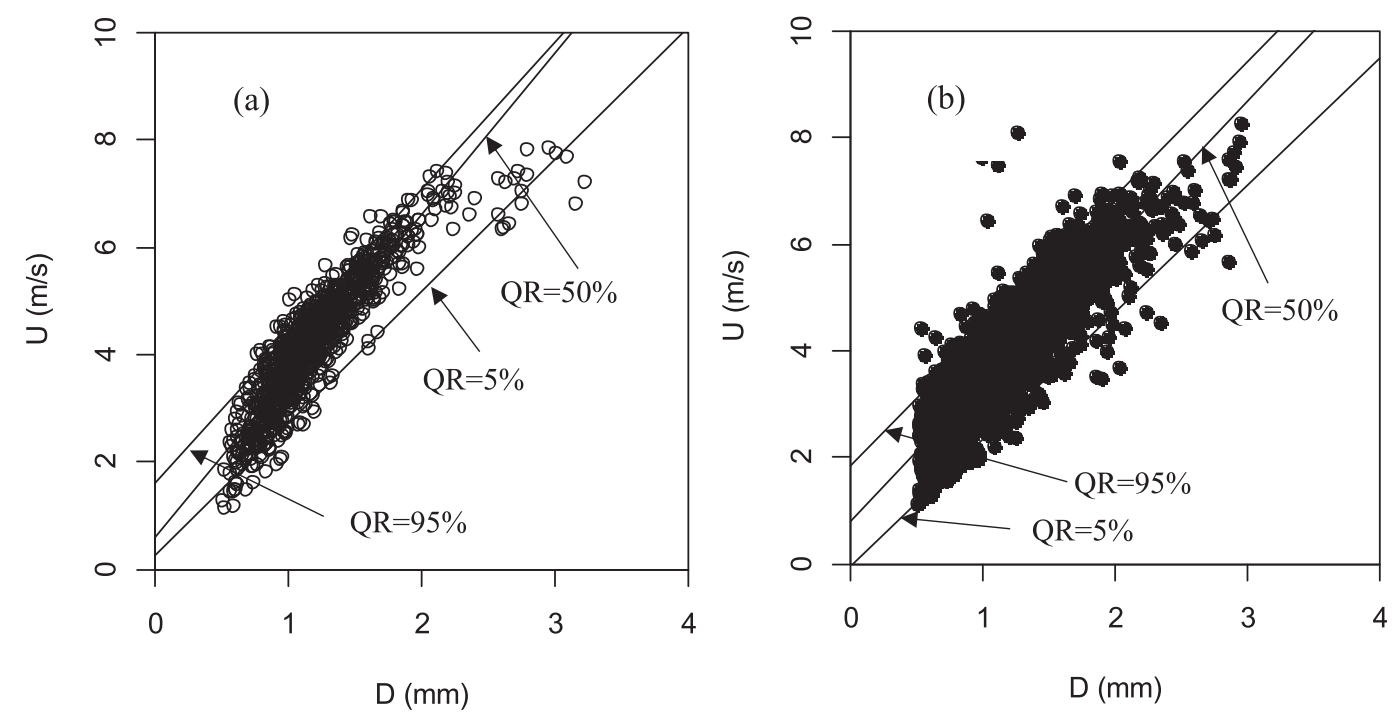

FIG. 5. Scatterplots of the fall speeds of (a) freezing (open circles) and (b) frozen raindrops (solid circles) observed during the field experiments as a function of the drop diameters are shown. Uncertainty associated with the fall speed measurements of freezing and frozen raindrops are also shown in the figure using quantile functions for the quantiles $0.05,0.5$, and 0.95 referred to as $\mathrm{QR}=5 \%, \mathrm{QR}=50 \%, \mathrm{QR}=95 \%$ in the plots, respectively.

utilized to estimate uncertainties accurately for the drop sizes between 2.6 and $3.2 \mathrm{~mm}$.

\section{b. Shapes of freezing and frozen raindrops}

Figures 6 and 7 present examples of freezing and frozen raindrop images captured by the HOD, respectively. Figure 6 includes both equilibrium-shaped freezing raindrops with different sizes (Figs. 6a-e) and a canted freezing raindrop (Fig. 6f). As can be seen from the figure, freezing raindrop shapes resemble warm raindrop shapes, which is not the case for the frozen raindrops. Majority of the observed frozen raindrops $(61 \%$ of the frozen raindrops with $D>1.0 \mathrm{~mm}$ ) exhibited a distinct feature such as a spicule, bulge, cavity, or aggregation. Note that, since shape deformities were identified from only side-view images, the provided percentage value is a conservative value, and the actual percentage of the observed frozen raindrops with shape deformities is expected to be larger. Figure 7 includes a variety of frozen raindrop shapes: undeformed frozen raindrops with rather spherical shapes (Figs. 7a-d), frozen raindrops with spicules (Figs. 7e-h), with bulges (Figs. 7i-1), with cavities/fractures (Figs. 7m,n), and coalesced frozen raindrops (Figs. 7o,p). Similar shape deformities of frozen raindrop surfaces were observed in both laboratory (Dye and Hobbs 1968; Takahashi 1975) and field experiments (Gibson and Stewart 2007). Moreover, Korolev et al. (2004) observed frozen raindrops of spherical shapes and with spicules and bulges using a Cloud Particle Imager (CPI) during a vertical sounding between 4400 and $5600 \mathrm{~m}$. Korolev et al. reported that frozen raindrops formed in the cloud may hold a spherical shape for the first $20 \mathrm{~min}$ of the drop formation. After this time period, the spherical frozen raindrop shape deforms and exhibits features such as bulges, spicules, aggregation, and cavities/fractures on the drop surfaces. Gibson et al. (2009) predicted the length of the spicule as $45 \%$ of the original drop diameter based on field observations using a high-resolution camera, and Wildeman et al. (2017) noted that the spicule length may grow up to the frozen raindrop diameter. Spicules may be oriented at various angles on the drop surface (as shown in Figs. 7e-h).

Figure 8 shows a sample of frozen raindrop images captured by the HOD $(\mathrm{a}-\mathrm{c})$, identified boundaries of these raindrops by the image processing software of the $\operatorname{HOD}\left(\mathrm{a}^{\prime}-\mathrm{c}^{\prime}\right)$, and the smallest rectangles enclosing these raindrops $\left(\mathrm{a}^{\prime \prime}-\mathrm{c}^{\prime \prime}\right)$. Maximum horizontal and vertical dimensions of a raindrop were determined using the smallest rectangle enclosing it, and these dimensions were used to calculate the axis ratio. Note that this approach has been used to calculate the axis ratios of warm raindrops (e.g., Chandrasekar et al. 1988; Andsager et al. 1999). Side-by-side comparison of the raw and processed images in this figure demonstrates a visual evaluation of the HOD's measurement capabilities for raindrops with and without shape deformities such as spicules and bulges. Shape deformities of frozen raindrops are not limited to those observed as a result of the hydrodynamic response of the raindrop during the freezing 

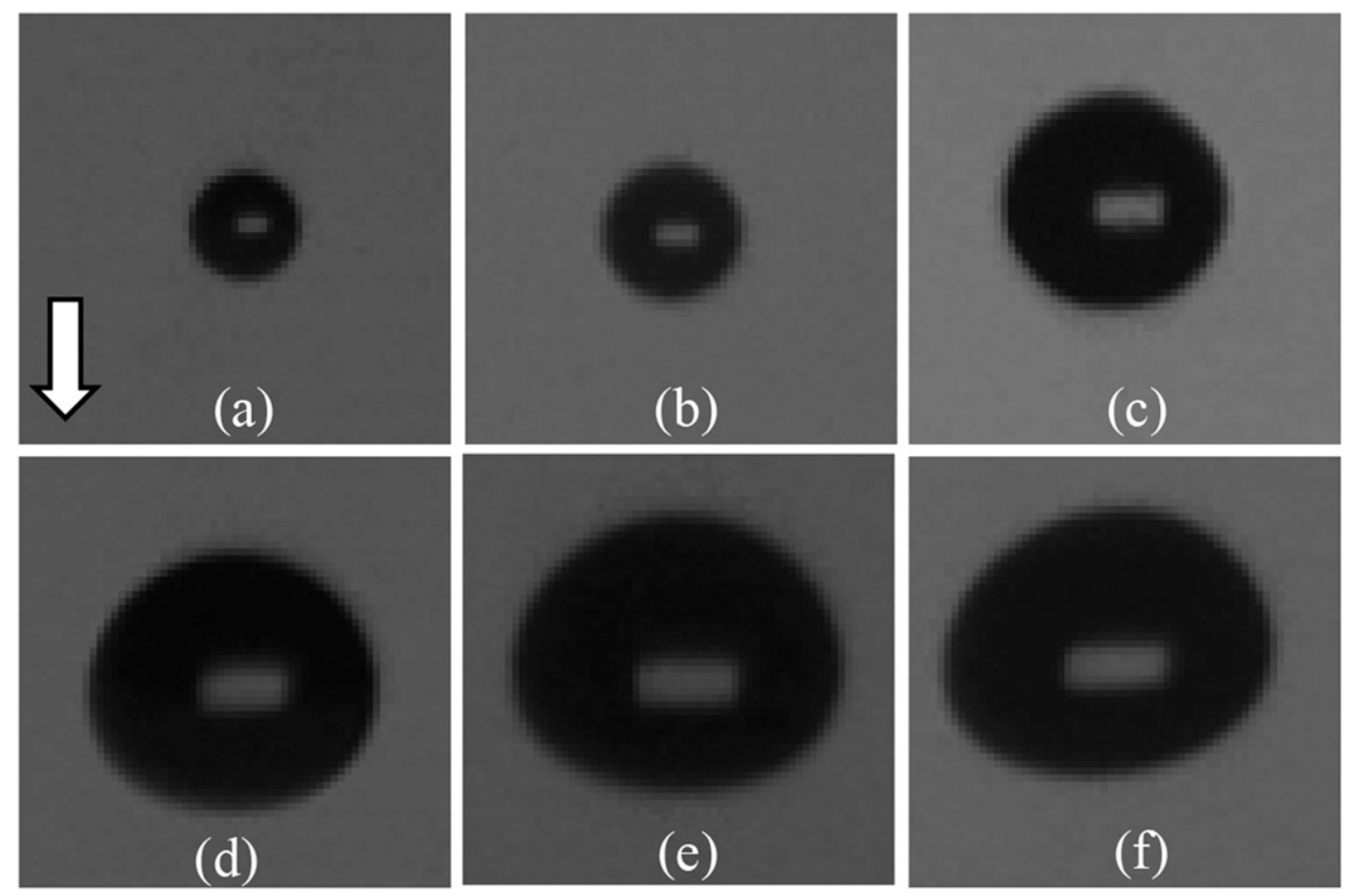

FIG. 6. Sample of HOD images for observed (a)-(e) equilibrium-shaped and (f) canted freezing raindrops with different sizes: (a) $D=1.1 \mathrm{~mm}, U=3.7 \mathrm{~m} \mathrm{~s}^{-1}$, and $\alpha=1$; (b) $D=1.4 \mathrm{~mm}, U=4.7 \mathrm{~m} \mathrm{~s}^{-1}$, and $\alpha=0.96$; (c) $D=$ $2.2 \mathrm{~mm}, U=6.8 \mathrm{~m} \mathrm{~s}^{-1}$, and $\alpha=0.97$; (d) $D=2.8 \mathrm{~mm}, U=6.9 \mathrm{~m} \mathrm{~s}^{-1}$, and $\alpha=0.88$; (e) $D=3 \mathrm{~mm}, U=7.8 \mathrm{~m} \mathrm{~s}^{-1}$, and $\alpha=0.86$; (f) $D=3 \mathrm{~mm}, U=8 \mathrm{~m} \mathrm{~s}^{-1}$, and $\alpha=0.83$.

process, but they also include coalesced frozen raindrops as a result of their collisional interaction. Sequential HOD images that show a coalesced frozen raindrop that formed as a result of the interaction of two frozen raindrops are presented in Fig. 9. As can be seen in these images, parent frozen raindrops are connected and fall as a single body. The shape deformities may introduce rotational movement of the frozen raindrops. As an example, Fig. 10 provides a sequence of images of a frozen raindrop with a spicule. As can be seen in this sequence of HOD images, the frozen raindrop tumbles during the fall due to the aerodynamic effects of the spicule. The blurry images (Figs. 10a-e) indicate that the frozen raindrop also translates horizontally toward the focal plane of the camera.

Field-observed axis ratios of freezing and frozen raindrops are presented in Fig. 11. In presenting these HOD observations, Parsivel bin sizes for the volume equivalent drop diameters were used to be consistent with the large body of literature that utilizes precipitation measurements by the Parsivel disdrometer. As can be seen in this figure, the dependency of the axis ratios of the freezing and frozen raindrops on the diameter exhibits a similar trend to the one for the warm raindrops. However, axis ratios of freezing and frozen raindrops are larger than those of warm raindrops for drop diameters larger than $1.5 \mathrm{~mm}$. Moreover, axis ratios of frozen raindrops in a given diameter bin had a larger standard deviation from the mean axis ratio of that bin than those of freezing raindrops for the entire size range of the raindrops observed by the HOD. The notable scatter of axis ratio measurements for frozen raindrops was due to the presence of shape deformities, which were highly variable in length and orientation. Axis ratio observations were also compared with model predictions. For this purpose, an available model by Khvorostyanov and Curry (2002) and an extension of Beard and Chuang (1987) equilibrium shape model for warm raindrops were used. In extending Beard and Chuang's model for freezing and frozen raindrops, we assumed that raindrop freezing starts at the outer surface of the drop as supported by the field observations of Gibson and Stewart (2007) and laboratory experiments of Takahashi (1975), and during the freezing process the drop shape remains unchanged while the drop volume increases due to the change in density and atmospheric conditions. Predicted equilibrium shapes of freezing and frozen raindrops using the extended Beard and Chuang shape model are shown in Fig. 12 for $D=1$ and $3 \mathrm{~mm}$ as an example. Figure 11 shows that the axis ratios of both freezing and frozen raindrops are close to unity for drops of diameter up to $1.5 \mathrm{~mm}$. Note that the axis ratio value 


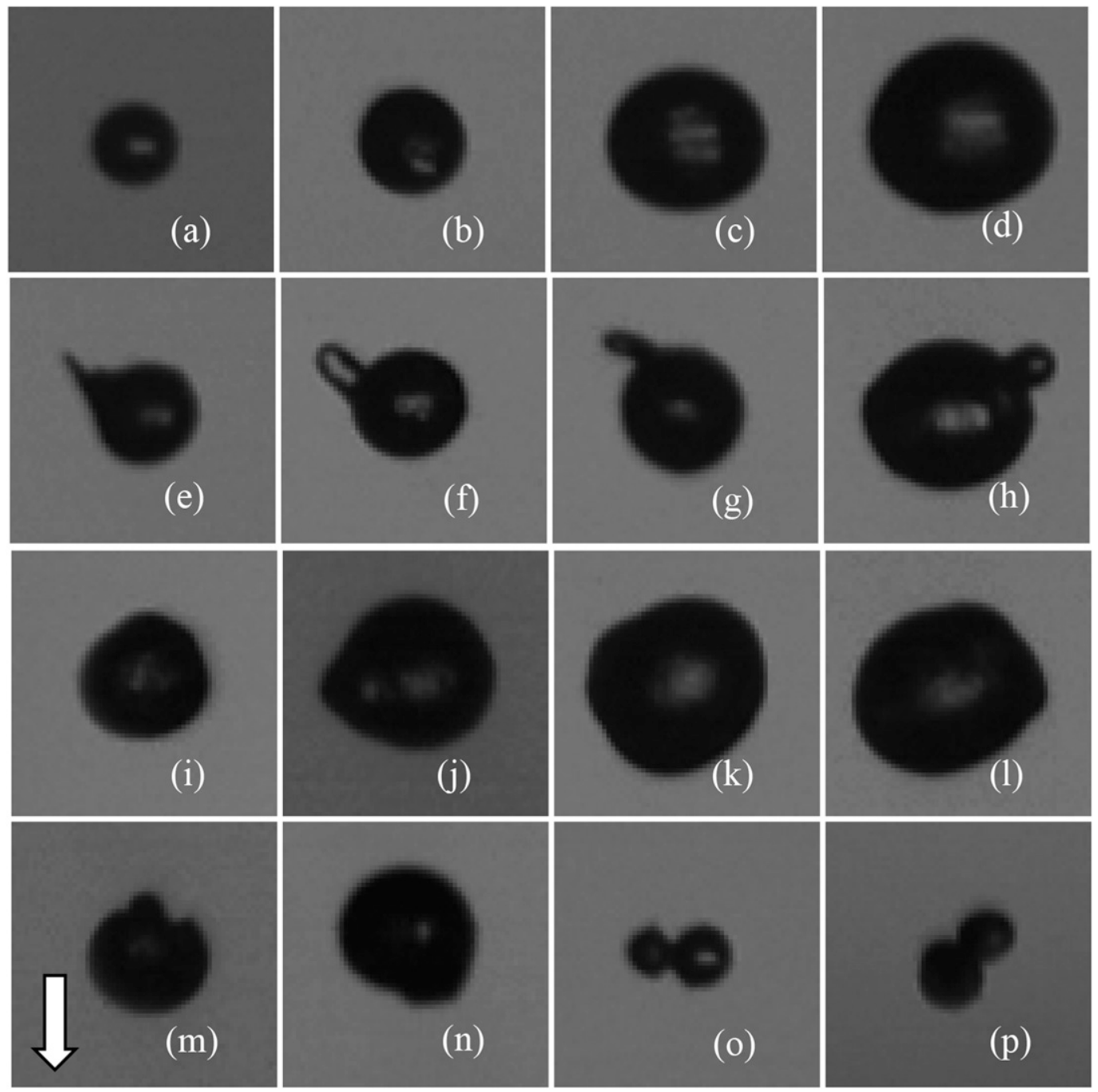

FIG. 7. Sample HOD images for observed frozen raindrops with and without shape deformities. Shown frozen raindrops without deformities have (a) $D=1.4 \mathrm{~mm}, U=5.4 \mathrm{~m} \mathrm{~s}^{-1}$, and $\alpha=0.95$; (b) $D=1.75 \mathrm{~mm}, U=5.9 \mathrm{~m} \mathrm{~s}^{-1}$, and $\alpha=1.04$; (c) $D=2.5 \mathrm{~mm}, U=7.4 \mathrm{~m} \mathrm{~s}^{-1}$, and $\alpha=0.92$; (d) $D=2.9 \mathrm{~mm}, U=7.7 \mathrm{~m} \mathrm{~s}^{-1}$, and $\alpha=0.93$. Shown frozen raindrops with spicules have (e) $D=1.8 \mathrm{~mm}, U=5.7 \mathrm{~m} \mathrm{~s}^{-1}$, and $\alpha=0.82$; (f) $D=2.05 \mathrm{~mm}, U=5.5 \mathrm{~m} \mathrm{~s}^{-1}$, and $\alpha=0.77$; (g) $D=2.1 \mathrm{~mm}, U=5.5 \mathrm{~m} \mathrm{~s}^{-1}$, and $\alpha=1.1$; (h) $D=2.8 \mathrm{~mm}, U=6.3 \mathrm{~m} \mathrm{~s}^{-1}$, and $\alpha=0.76$. Shown frozen raindrops with bulges have (i) $D=2.0 \mathrm{~mm}, U=6.5 \mathrm{~m} \mathrm{~s}^{-1}$, and $\alpha=0.97$; (j) $D=2.6 \mathrm{~mm}, U=6.9 \mathrm{~m} \mathrm{~s}^{-1}$, and $\alpha=0.88$; (k) $D=2.9 \mathrm{~mm}, U=7.3 \mathrm{~m} \mathrm{~s}^{-1}$, and $\alpha=1$; (1) $D=3.0 \mathrm{~mm}, U=8.1 \mathrm{~m} \mathrm{~s}^{-1}$, and $\alpha=0.9$. Shown frozen raindrops with cavities have: (m) $D=1.9 \mathrm{~mm}, U=5.3 \mathrm{~m} \mathrm{~s}^{-1}$, and $\alpha=0.96$; (n) $D=2.2 \mathrm{~mm}, U=6.6 \mathrm{~m} \mathrm{~s}^{-1}$, and $\alpha=$ 1.0. Shown coalesced frozen raindrops have (o) $D=1.6 \mathrm{~mm}, U=3.3 \mathrm{~m} \mathrm{~s}^{-1}$, and $\alpha=0.6$; (p) $D=1.6 \mathrm{~mm}, U=$ $3.8 \mathrm{~m} \mathrm{~s}^{-1}$, and $\alpha=1.0$.

of unity indicates that drops are spherical in shape, and deviations from sphericity become notable for equilibrium-shaped warm raindrops that are larger than approximately $1 \mathrm{~mm}$ in diameter. The comparisons of the predicted freezing and frozen equilibrium shapes in Fig. 12 demonstrate the expected difference in the equilibrium shapes of these two different hydrometeors due to drop properties and ambient conditions. Based upon the HOD observations during the precipitation events presented in this article, empirical axis ratio parameterizations for the freezing [Eq. (17)] and frozen [Eq. (18)] raindrops are developed as follows. In developing the parameterization for the freezing raindrops [Eq. (17)], 2.45- and 3.35-mm-diameter bins were again omitted as those bins contain only 2 and 3 freezing raindrops, respectively:

$$
\begin{gathered}
\alpha_{\text {freezing }}=-2.740 D^{2}+0.467 D+0.978, \\
\alpha_{\text {frozen }}=-2.062 D^{2}+0.393 D+0.959 .
\end{gathered}
$$




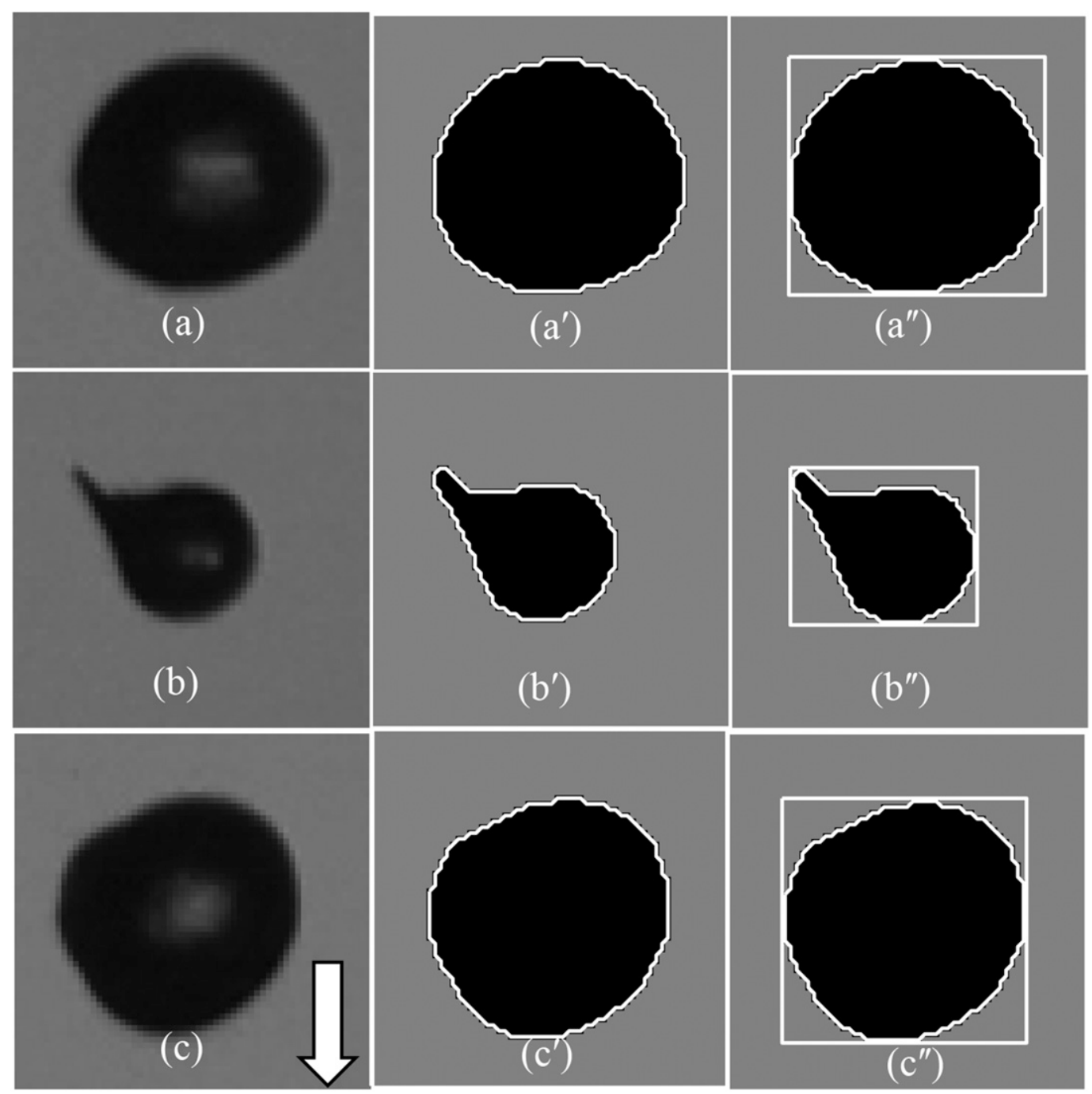

FIG. 8. Frozen raindrop $\left(D=2.9 \mathrm{~mm}, U=7.7 \mathrm{~m} \mathrm{~s}^{-1}\right.$, and $\left.\alpha=0.93\right)$ without a deformity: (a) raw HOD image, $\left(\mathrm{a}^{\prime}\right)$ processed image for boundary detection, $\left(\mathrm{a}^{\prime \prime}\right)$ processed image for axis ratio determination. Frozen raindrop $(D=$ $1.8 \mathrm{~mm}, U=5.7 \mathrm{~m} \mathrm{~s}^{-1}$, and $\alpha=0.82$ ) with a spicule: (b) raw HOD image, $\left(\mathrm{b}^{\prime}\right)$ processed image for boundary detection, $\left(\mathrm{b}^{\prime \prime}\right)$ processed image for axis ratio determination. Frozen raindrop $\left(D=2.9 \mathrm{~mm}, U=7.3 \mathrm{~m} \mathrm{~s}^{-1}\right.$, and $\alpha=$ 1.0) with bulges: (c) raw HOD image, $\left(\mathrm{c}^{\prime}\right)$ processed image for boundary detection, $\left(\mathrm{c}^{\prime \prime}\right)$ processed image for axis ratio determination.

Here, $D$ is in centimeters. Pearson's correlation coefficient $r$ for the field measurements and the proposed axis ratio parameterizations for freezing and frozen raindrops are 0.93 and 0.89, respectively. In Fig. 11, the predictions by Khvorostyanov and Curry's (2002) model, the extended Beard and Chuang's (1987) model, and the empirical parameterizations in Eqs. (16) and (17) were compared with the axis ratio observations from the field experiments. This figure shows the close fit of the predictions by the developed empirical parameterizations. As can be seen in this figure, the match between the observed data and the predictions decreased from extended Beard and Chuang model, to the original Beard and
Chuang model, which is for warm raindrops, and then to Khvorostyanov and Curry's model. This order for the closeness of the matches was same for both freezing and frozen raindrops.

Frozen raindrops and graupels may act as hailstone embryos. The occurrence percentages of the two embryo types correlate well with the average cloud-base temperature (Knight 1981). Knight and Knight (1974) reported that embryos of approximately $20 \%$ of their hailstone collection were frozen raindrops. Later, Knight (1981) reported a wide range of percentages for frozen raindrops and graupel as hailstone embryos for hailstone collections at different geographic locations. These percentages for 

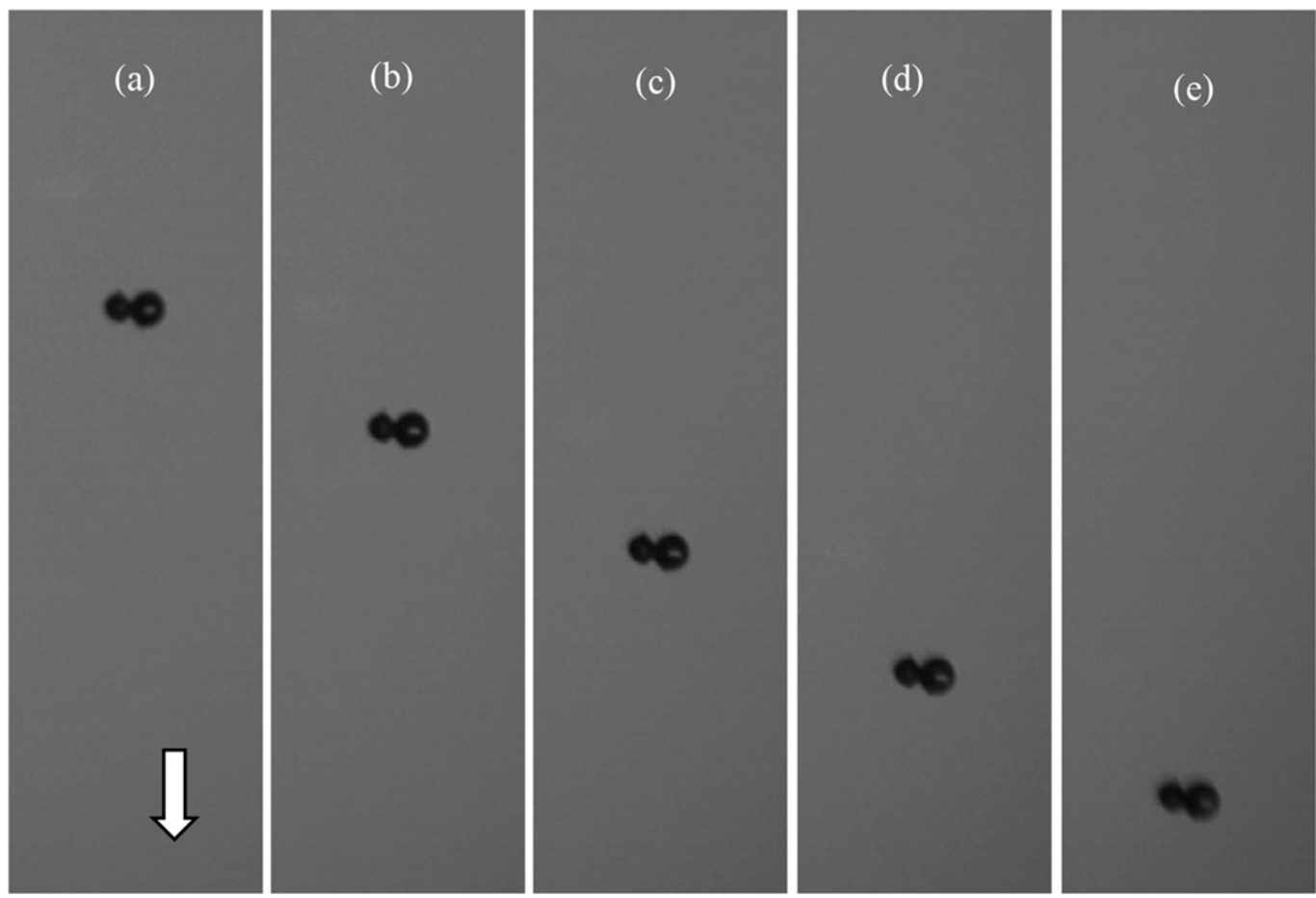

FIG. 9. Sequence of HOD images of a coalesced frozen raindrop with a fall speed of $3.3 \mathrm{~m} \mathrm{~s}^{-1}$. The collision of two frozen parent raindrops with $D=0.9$ and $0.7 \mathrm{~mm}$ resulted in the coalesced frozen raindrop seen in the images. Vertical arrow represents the direction of gravity.

frozen raindrops as embryos were as large as $69 \%$ and $83 \%$ for hailstones (with largest dimension larger than $25 \mathrm{~mm}$ ) collected from South Africa (Lowveld) and Oklahoma, respectively. Knight (1986) reported that small hail from northeastern Colorado, which has primarily conical graupel as hailstone embryos, is significantly less spherical than hail of comparable size from Oklahoma, which has primarily frozen raindrops as hailstone embryos. The larger sphericity of the hailstones from Oklahoma than those from Colorado is likely a direct reflection of the larger sphericity of frozen raindrops than graupel. The hailstone collection from Oklahoma has an average axis ratio of approximately 0.95 for the hailstones of $1-5 \mathrm{~mm}$ in size (Knight 1986). In our field observations, the average frozen raindrop axis ratio for the entire frozen raindrop dataset was 0.97 with a standard deviation of 0.09 , matching closely with the axis ratios of hailstones with frozen raindrops as embryos.

\section{Conclusions}

Fall speeds and shapes of freezing and frozen raindrops were investigated through a unique field dataset that contains high-quality, sequential HOD images. The HOD images of freezing and frozen raindrops were digitally processed for accurate fall speed and shape measurements of the observed raindrops. By utilizing the fall speed and shape measurements, the drag coefficients of the observed freezing and frozen raindrops were calculated. It was found that, for raindrops smaller than $1.42 \mathrm{~mm}$ in volume equivalent diameter, freezing and frozen raindrops have higher drag coefficients than those of warm raindrops for a given drop size. We developed two separate $C_{d}$-Re relationships, which follow Abraham's (1970) functional form, for freezing and frozen raindrops based on our field observations. Fall speeds of observed freezing and frozen raindrops exhibited a similar dependency on the drop diameter to those of warm raindrops. Fall speed observations of the freezing and frozen raindrops were compared with the predictions of the models by Beard (1976), Khvorostyanov and Curry (2002, 2005), and Heymsfield and Westbrook (2010). In general, there is a good agreement between the observations and the predictions of all three models. More specifically, freezing raindrops show a better agreement with the predictions of Beard's model than those of the other two models for drop sizes up to $2.3 \mathrm{~mm}$ in diameter. For freezing raindrops with larger sizes, the number of observations was small and morphodynamic disturbances (oscillations and canting) were present, which limit conclusions on the fall speeds of these larger freezing raindrops. Fall speeds of the observed frozen raindrops 


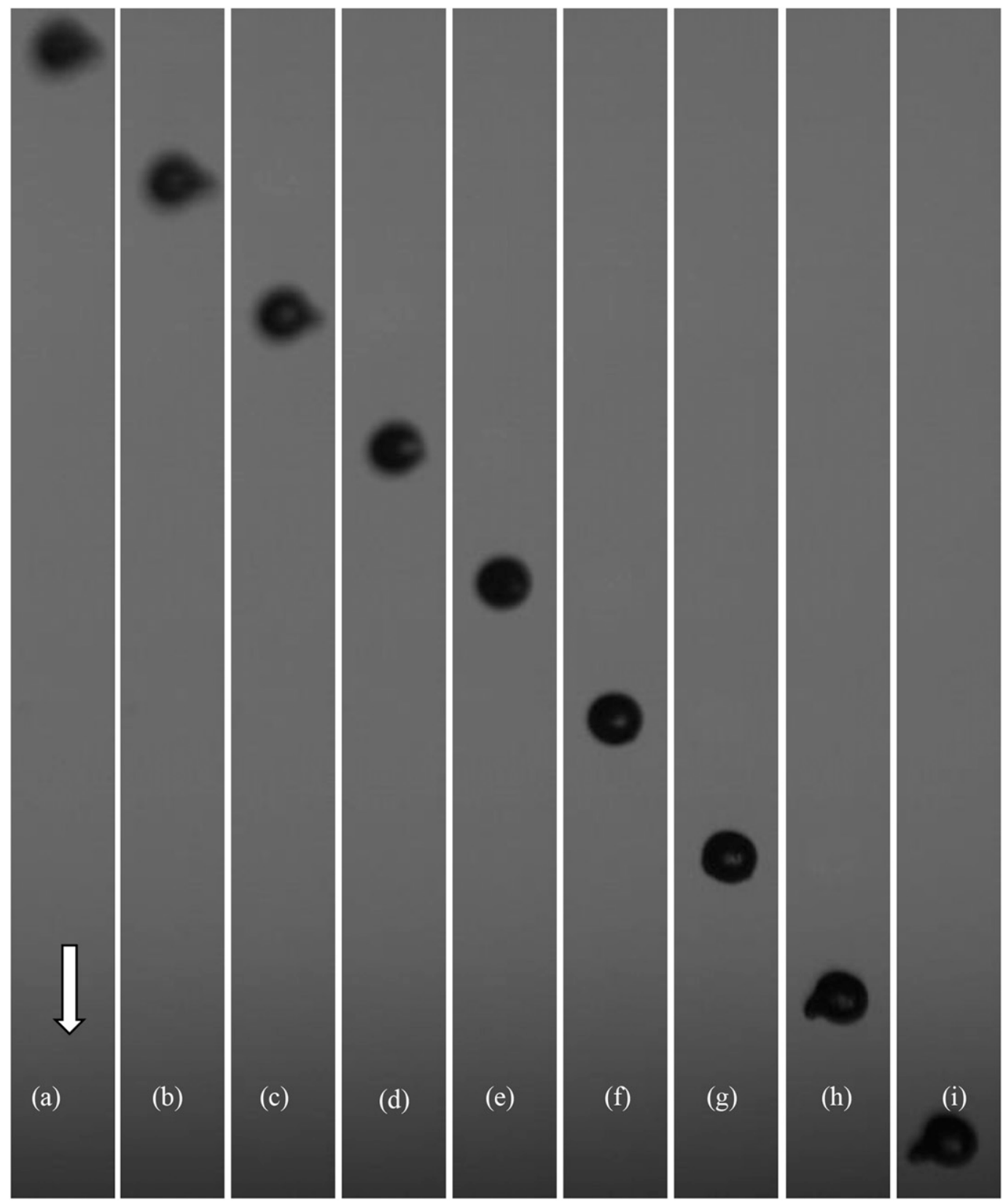

FIG. 10. Sequence of HOD images of a frozen raindrop with a spicule. The sharpness of the frozen raindrop changes as the drop also translates along the camera axis, and the change in the spicules orientation indicates the tumbling behavior of the frozen raindrop. Vertical arrow represents the direction of gravity.

show a close agreement with both Khvorostyanov and Curry's model and Heymsfield and Westbrook's model for the entire size range. However, observed frozen raindrops exhibited large fall speed deviations from the mean values. We attribute these fall speed deviations to the presence of the variety of shape deformities and the wide range of their orientation.

While the observed freezing raindrops had similar shapes to the warm raindrops, many of the observed frozen raindrops exhibited various deformities including spicules, bulges, and cavities, as well as aggregation due to coalescence of colliding frozen raindrops during fall. Average axis ratio values of both freezing and frozen raindrops up to $2 \mathrm{~mm}$ in diameter were found to be between 0.95 and 1 . For diameters larger than $2 \mathrm{~mm}$, frozen raindrops were observed to have larger axis ratio values than those of freezing raindrops, and the axis ratio values of the freezing and frozen raindrops decreased 

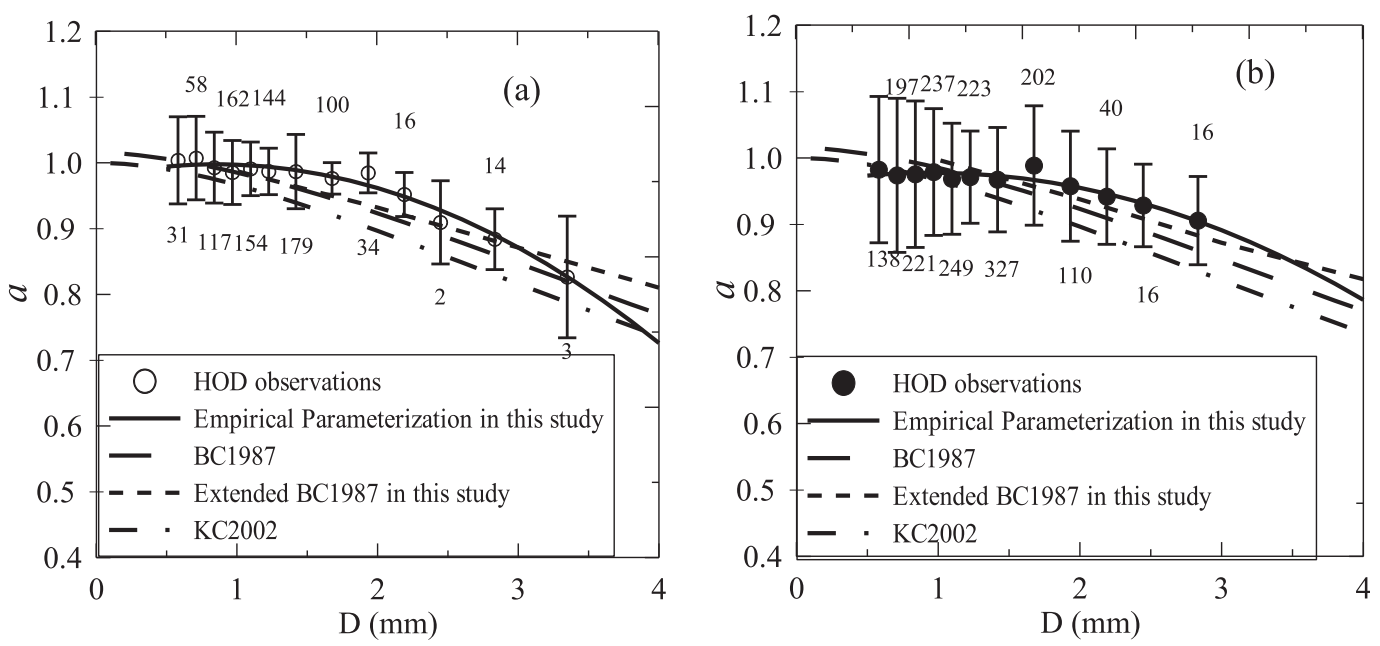

FIG. 11. Observed axis ratios of (a) freezing (open circles) and (b) frozen raindrops (solid circles) as a function of drop diameter. HOD observations are compared with the predicted axis ratios by three different models: Khvorostyanov and Curry (2002) (KC2002, dash-dot line), Beard and Chuang (1987) (BC1987, long dashed line), and extended model of Beard and Chuang (1987) for freezing and frozen raindrops in this study (extended BC1987 in this study, dashed line). Observations are also compared with the empirical parameterizations [Eqs. (17) and (18) for freezing and frozen raindrops, respectively] developed in this study referred as empirical parameterization in this study (solid line). Note that axis ratio predictions by Beard and Chuang (1987) are for warm raindrops and are shown here for comparison. Axis ratio predictions by Khvorostyanov and Curry (2002) is based upon the drop shape considerations irrespective of freezing, frozen, or warm raindrops considering the drops being oblate spheroids for $D>1 \mathrm{~mm}$. For each diameter bin, standard deviation of axis ratios from the average axis ratio of the bin (vertical bars) and number of drops are shown.

gradually to approximately 0.83 for freezing raindrops with a diameter of $3.35 \mathrm{~mm}$ and to approximately 0.9 for frozen raindrops with a diameter of $2.83 \mathrm{~mm}$. Equilibrium shape model by Beard and Chuang (1987) was extended to ascertain freezing and frozen raindrop shapes. Moreover, based upon field observations, individual empirical axis ratio parameterizations for freezing and frozen raindrops were developed [see Eqs. (17) and (18)]. The predictions of Beard and Chuang's (1987) original model for warm raindrops, the extended Beard and Chuang's (1987) model in this study, developed empirical parameterizations in Eqs. (17) and (18), and Khvorostyanov and Curry's (2002)
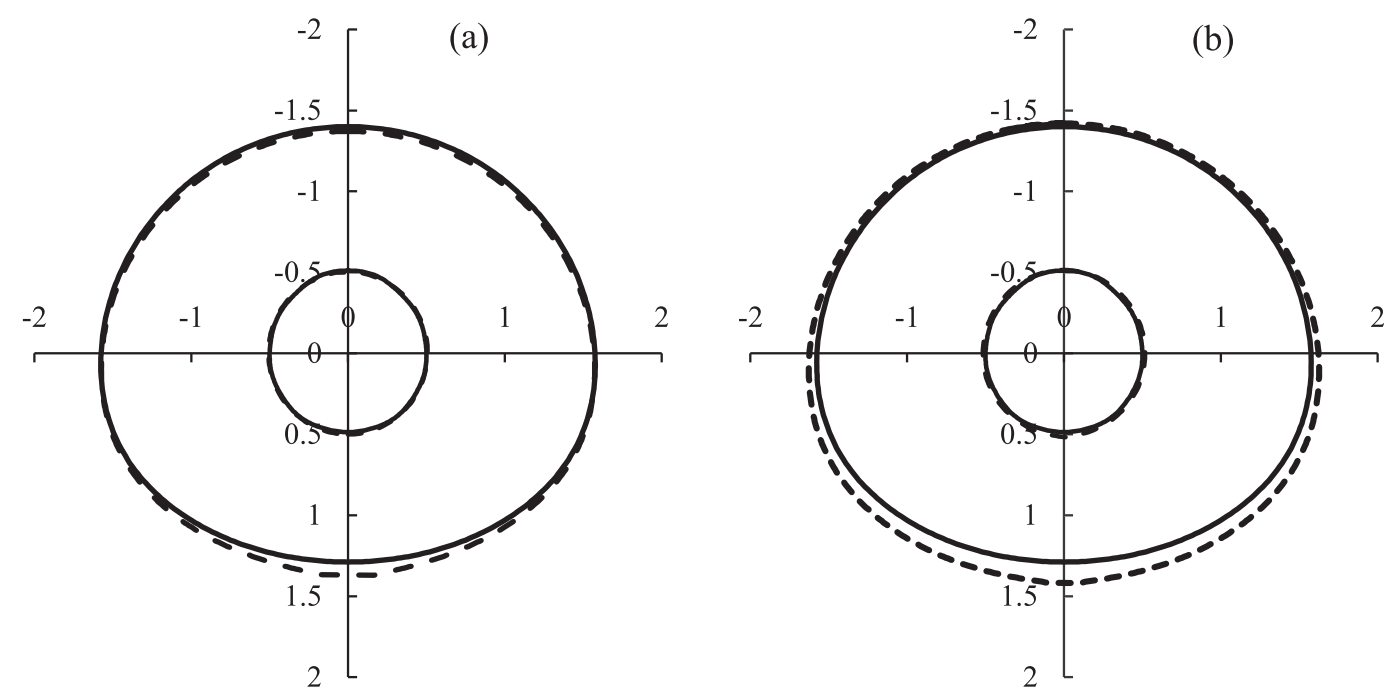

FIG. 12. Predicted shapes of equilibrium-shaped warm raindrops (solid line) and freezing and frozen raindrops without deformities (dotted line) by the extended model of Beard and Chuang (1987). Axes are in millimeters. (a) Freezing and warm raindrops with $D=1 \mathrm{~mm}$ and $D=3 \mathrm{~mm}$ and (b) frozen and warm raindrops with $D=1 \mathrm{~mm}$ and $D=3 \mathrm{~mm}$. 
TABLE A1. Beard's fall speed parameterization for raindrops larger than and smaller than $1.07 \mathrm{~mm}$. Notations: $\sigma$ is surface tension of raindrop, $B_{0}$ is modified Bond number, $N_{p}$ is physical property number, $C_{\mathrm{sc}}$ is slip correction factor, and $l$ is mean free path of air molecules.

\begin{tabular}{|c|c|}
\hline Beard's fall speed parameterization for raindrops larger than $1.07 \mathrm{~mm}$ & $\begin{array}{l}\text { Beard's fall speed parameterization for raindrops with } \\
\text { diameter less than } 1.07 \mathrm{~mm}\end{array}$ \\
\hline $\begin{aligned} c_{3} & =4\left(\rho_{b}-\rho_{a}\right) g / 3 \sigma \\
B_{o} & =c_{3} D^{2} \\
N_{p} & =\sigma^{3} \rho_{a}^{2} /\left[\mu^{4}\left(\rho_{b}-\rho_{a}\right) g\right]\end{aligned}$ & $\begin{aligned} C_{2} & =4 \rho_{a}\left(\rho_{b}-\rho_{a}\right) g / 3 \mu^{2} \\
X & =C_{2} D^{3} \\
Z & =\log _{\mathrm{e}}(X)\end{aligned}$ \\
\hline$Z=\log _{e} B_{o} N_{p}^{1 / 6}$ & $Y=b_{o}+b_{1} Z+b_{2} Z^{2}+b_{3} Z^{3}+b_{4} Z^{4}+b_{5} Z^{5}+b_{6} Z^{6}$ \\
\hline$Y=b_{o}+b_{1} Z+b_{2} Z^{2}+b_{3} Z^{3}+b_{4} Z^{4}+b_{5} Z^{5}$ & $\begin{aligned} b_{0}= & -3.18657 ; b_{1}=+0.992696 ; b_{2}=-0.00153193 ; b_{3}= \\
& -0.000987059 ; b_{4}=-0.000578878 ; b_{5}= \\
& +0.0000855176 ; b_{6}=-0.00000327815\end{aligned}$ \\
\hline $\begin{array}{l}b_{0}=-5.00015 ; b_{1}=+5.23778 ; b_{2}=-2.04914 ; b_{3}=+0.475294 \\
b_{4}=-0.0542819 ; b_{5}=+0.00238449\end{array}$ & $C_{\mathrm{sc}}=1+2.51 l / D$ \\
\hline $\operatorname{Re}=N_{p}^{1 / 6} \exp (Y)$ & $l=l_{0}\left(\mu / \mu_{0}\right)\left(p_{0} / p\right)\left(T / T_{0}\right)^{1 / 2}$ \\
\hline \multirow[t]{6}{*}{$U_{t}=\mu \operatorname{Re} /\left(\rho_{a} D\right)$} & $l_{0}=6.62 \times 10^{-6} \mathrm{~cm}$ \\
\hline & $p_{0}=1013.25 \mathrm{mb}$ \\
\hline & $\mu_{0}=0.0001818 \mathrm{~g} \mathrm{~cm}^{-1} \mathrm{~s}^{-1}$ \\
\hline & $T_{0}=293.15 \mathrm{~K}$ \\
\hline & $\mathrm{Re}=C_{\mathrm{sc}} \exp (Y)$ \\
\hline & $U_{t}=\mu \operatorname{Re} /\left(\rho_{a} D\right)$ \\
\hline
\end{tabular}

model were compared with the axis ratio observations from the field experiments. Given the empirical nature of Eqs. (17) and (18), the predictions of these equations closely matched the observations. These comparisons verified that the extended Beard and Chuang's model has improved predictions for freezing and frozen raindrops as compared to the predictions of Beard and Chuang's original model that is for warm raindrops. Khvorostyanov and Curry's model showed a general trend of underestimating the observed axis ratios for both freezing and frozen raindrops.

In various applications (e.g., remote sensing of precipitation), fall speeds of hydrometeors are assumed to be terminal. However, for the case of warm raindrops, several recent studies documented nonterminal raindrop observations (e.g., see Fig. 4 of Testik et al. 2006; Montero-Martínez et al. 2009; Thurai et al. 2013; Larsen et al. 2014). These observations further suggest that fall speed of hydrometeors is an important source of uncertainty in a given application. For example, Pei et al. (2014) showed that rain rate estimation errors by dualpolarization weather radars can be approximately $20 \%$ for observed deviations of fall speeds and axis ratios of warm raindrops from the predicted terminal fall speeds and equilibrium axis ratios. Pei et al. further showed the potential for much larger rain rate estimation errors due to the high sensitivity of dual-polarization radar rain rate retrievals on raindrop fall velocity and axis ratio predictions. In addition to the radar meteorologists, we expect this study to have a variety of beneficiaries. For example, (i) cloud and numerical weather prediction modelers use the information of shapes and fall speeds of freezing and frozen precipitation to better understand the evolution and microphysical processes of various precipitation types (e.g., Thériault et al. 2006, 2010; Thériault and Stewart 2010; Chen et al. 2011), (ii) velocity and kinetic energy of freezing and frozen hydrometeors are important for the insurance and roofing industries to calculate property damages due to such precipitation (e.g., Heymsfield et al. 2014; Schuster et al. 2006), and (iii) improved measurements of parameters such as intensity and accumulation of freezing and frozen rainfall are essential for the aviation industry for safer operations under such conditions (e.g., Gultepe et al. 2019). Therefore, these observations on the fall speeds and shapes of freezing and frozen raindrops presented in this study are valuable in increasing our knowledge base in hydrometeorology and hydrology with various potential beneficiaries in different fields. It is desirable to enlarge the dataset collected in this study to enable improved statistical analyses and characterizations of the relevant quantities and to include samples from different environmental conditions, geographic locations, and collection periods.

Acknowledgments. This research was supported by the funds provided by the National Science Foundation under Grants AGS-1612681, AGS-1144846, and AGS1741250 to the second author (FYT). The first author was a graduate student under the guidance of FYT.

\section{APPENDIX}

\section{Fall Speed Parameterization of Beard (1976)}

Table A1 compares Beard's fall speed parameterization for raindrops larger than and smaller than $1.07 \mathrm{~mm}$. 


\section{REFERENCES}

Abraham, F. F., 1970: Functional dependence of drag coefficient of a sphere on Reynolds number. Phys. Fluids, 13, 2194-2195, https://doi.org/10.1063/1.1693218.

Andsager, K., K. V. Beard, and N. F. Laird, 1999: Laboratory measurements of axis ratios for large raindrops. J. Atmos. Sci., 56, 2673-2683, https://doi.org/10.1175/1520-0469(1999) 056<2673:LMOARF $>2.0$.CO;2.

Angulo-Martínez, M., S. Beguería, B. Latorre, and M. FernándezRaga, 2018: Comparison of precipitation measurements by OTT Parsivel2 and Thies LPM optical disdrometers. Hydrol. Earth Syst. Sci., 22, 2811-2837, https://doi.org/10.5194/hess-222811-2018.

Atlas, D., R. C. Srivastava, and R. S. Sekhon, 1973: Doppler radar characteristics of precipitation at vertical incidence. Rev. Geophys., 11, 1-35, https://doi.org/10.1029/RG011i001p00001.

Bally, O., 1935: Über eine eigenartige Eiskrystallbildung. Helv. Chim. Acta, 18, 475-476, https://doi.org/10.1002/ hlca.19350180164.

Beard, K. V., 1976: Terminal velocity and shape of cloud and precipitation drops aloft. J. Atmos. Sci., 33, 851-864, https://doi.org/10.1175/1520-0469(1976)033<0851:TVASOC > 2.0.CO;2.

—- and C. Chuang, 1987: A new model for the equilibrium shape of raindrops. J. Atmos. Sci., 44, 1509-1524, https://doi.org/ 10.1175/1520-0469(1987)044<1509:ANMFTE >2.0.CO;2.

Blanchard, D. C., 1951: A verification of the balley-dorsey theory of spicule formation on sleet pellets. J. Meteor., $\mathbf{8}$, 268-269, https://doi.org/10.1175/1520-0469(1951)008<0268: AVOTBD $>2.0 . C O ; 2$.

_ 1957: The supercooling, freezing and melting of giant waterdrops at terminal velocity in air. Artificial Stimulation of Rain, H. K. Weickmann and W. Smith, Eds., Pergamon Press, 233-245.

Böhm, J. P., 1989: A general equation for the terminal fall speed of solid hydrometeors. J. Atmos. Sci., 46, 2419-2427, https://doi.org/ 10.1175/1520-0469(1989)046<2419:AGEFTT>2.0.CO;2.

Braham, R. R., 1964: What is the role of ice in summer rain showers? J. Atmos. Sci., 21, 640-645, https://doi.org/10.1175/ 1520-0469(1964)021<0640:WITROI >2.0.CO;2.

Brooks, C. F., 1920: The nature of sleet and how it is formed. Mon. Wea. Rev., 48, 69-72, https://doi.org/10.1175/1520-0493(1920) 48<69b:TNOSAH $>2.0 . \mathrm{CO} ; 2$.

Bruning, E. C., W. D. Rust, T. J. Schuur, D. R. MacGorman, P. R. Krehbiel, and W. Rison, 2007: Electrical and polarimetric radar observations of a multicell storm in TELEX. Mon. Wea. Rev., 135, 2525-2544, https://doi.org/10.1175/MWR3421.1.

Chandrasekar, V., W. A. Cooper, and V. N. Bringi, 1988: Axis ratios and oscillations of raindrops. J. Atmos. Sci., 45, 1323-1333, https://doi.org/10.1175/1520-0469(1988)045<1323: ARAOOR $>2.0 . C O ; 2$.

Chen, B., W. Hu, and J. Pu, 2011: Characteristics of the raindrop size distribution for freezing precipitation observed in southern China. J. Geophys. Res., 116, D06201, https://doi.org/ 10.1029/2010JD015305.

Dorsey, N. E., 1938: Supercooling and freezing of water. J. Res. Natl. Bur. Stand., 20, 799-808, https://doi.org/10.6028/jres.020.006.

Durant, A. J., and R. A. Shaw, 2005: Evaporation freezing by contact nucleation inside-out. Geophys. Res. Lett., 32, L20814, https://doi.org/10.1029/2005GL024175.

Dye, J. E., and P. V. Hobbs, 1968: The influence of environmental parameters on the freezing and fragmentation of suspended water drops. J. Atmos. Sci., 25, 82-96, https://doi.org/10.1175/ 1520-0469(1968)025<0082:TIOEPO>2.0.CO;2.

Friederichs, P., and A. Hense, 2007: Statistical downscaling of extreme precipitation events using censored quantile regression. Mon. Wea. Rev., 135, 2365-2378, https://doi.org/ 10.1175/MWR3403.1.

Gibson, S. R., and R. E. Stewart, 2007: Observations of ice pellets during a winter storm. Atmos. Res., 85, 64-76, https://doi.org/ 10.1016/j.atmosres.2006.11.004.

- - - and W. Henson, 2009: On the variation of ice pellet characteristics. J. Geophys. Res., 114, D09207, https://doi.org/ 10.1029/2008JD011260.

Gultepe, I., and Coauthors, 2019: A review of high impact weather for aviation meteorology. Pure Appl. Geophys., 176, 1869-1921, https://doi.org/10.1007/s00024-019-02168-6.

Gunn, R., and G. D. Kinzer, 1949: The terminal velocity of fall for water droplets in stagnant air. J. Meteor., 6, 243-248, https://doi.org/10.1175/1520-0469(1949)006<0243:TTVOFF> 2.0.CO;2.

Hallett, J., 1960: Crystal growth and the formation of spikes in the surface of supercooled water. J. Glaciol., 3, 698-704, https:// doi.org/10.1017/S0022143000017998.

Heymsfield, A. J., and C. D. Westbrook, 2010: Advances in the estimation of ice particle fall speeds using laboratory and field measurements. J. Atmos. Sci., 67, 2469-2482, https://doi.org/ 10.1175/2010JAS3379.1.

—, I. M. Giammanco, and R. Wright, 2014: Terminal velocities and kinetic energies of natural hailstones. Geophys. Res. Lett., 41, 8666-8672, https://doi.org/10.1002/2014GL062324.

Hill, L., E. Lozowski, and R. D. Sampson, 2004: Experiments on ice spikes and a simple growth model. J. Glaciol., 50, 375-381, https://doi.org/10.3189/172756504781829954.

Hobbs, P. V., and A. L. Rangno, 1985: Ice particle concentrations in clouds. J. Atmos. Sci., 42, 2523-2549, https://doi.org/10.1175/ 1520-0469(1985)042<2523:IPCIC>2.0.CO;2.

Hogan, A. W., 1985: Is sleet a contact nucleation phenomenon? Proc. 42nd Eastern Snow Conf., Montreal, QC, Canada, Eastern Snow Conference, 290-294.

Holten, V., J. V. Sengers, and M. A. Anisimov, 2014: Equation of state for supercooled water at pressures up to $400 \mathrm{MPa}$. J. Phys. Chem. Ref. Data, 43, 043101, https://doi.org/10.1063/ 1.4895593.

Jaffrain, A., A. Studzinski, and A. Berne, 2011: A network of disdrometers to quantify the small-scale variability of the raindrop size distribution. Water Resour. Res., 47, W00H06, https://doi.org/10.1029/2010WR009872.

Jones, K. F., 1998: A simple model for freezing rain ice loads. Atmos. Res., 46, 87-97, https://doi.org/10.1016/S0169-8095(97) 00053-7.

Jung, S., M. K. Tiwari, N. V. Doan, and D. Poulikakos, 2012: Mechanism of supercooled droplet freezing on surfaces. Nat. Commun., 3, 615, https://doi.org/10.1038/ncomms1630.

Khain, A. P., and M. Pinsky, 2018: Physical Processes in Clouds and Cloud Modeling. Cambridge University Press, 640 pp.

Khvorostyanov, V. I., and J. A. Curry, 2002: Terminal velocities of droplets and crystals: Power laws with continuous parameters over the size spectrum. J. Atmos. Sci., 59, 1872-1884, https://doi.org/10.1175/1520-0469(2002)059<1872: TVODAC $>2.0 . \mathrm{CO} ; 2$.

, and - 2005: Fall velocities of hydrometeors in the atmosphere: Refinements to a continuous analytical power law. J. Atmos. Sci., 62, 4343-4357, https://doi.org/10.1175/ JAS3622.1. 
Kikuchi, K., T. Kameda, K. Higuchi, and A. Yamashita, 2013: A global classification of snow crystals, ice crystals, and solid precipitation based on observations from middle latitudes to polar regions. Atmos. Res., 132-133, 460-472, https://doi.org/ 10.1016/j.atmosres.2013.06.006.

Knight, C. A., 1998: Answer to question \#65. What conditions determine crystal growth? The triangular ice spike. Amer. J. Phys., 66, 1041-1042, https://doi.org/10.1119/1.19059.

— Sci., 31, 1174-1176, https://doi.org/10.1175/1520-0469(1974) 031<1174:DFIC > 2.0.CO;2.

Knight, N. C., 1981: The climatology of hailstone embryos. J. Appl. Meteor., 20, 750-755, https://doi.org/10.1175/1520-0450(1981) $020<0750$ :TCOHE $>2.0$.CO;2.

_ 1986: Hailstone shape factor and its relation to radar interpretation of hail. J. Climate Appl. Meteor., 25, 1956-1958, https://doi.org/10.1175/1520-0450(1986)025<1956:HSFAIR > 2.0.CO;2.

Koenig, L. R., 1963: The glaciating behavior of small cumulonimbus clouds. J. Atmos. Sci., 20, 29-47, https://doi.org/10.1175/ 1520-0469(1963)020<0029:TGBOSC > 2.0.CO;2.

Kolomeychuk, R. J., D. C. McKay, and J. V. Iribarne, 1975: The fragmentation and electrification of freezing drops. J. Atmos. Sci., 32, 974-979, https://doi.org/10.1175/1520-0469(1975) 032<0974:TFAEOF $>2.0$. CO;2.

Korolev, A. V., M. P. Bailey, J. Hallett, and G. A. Isaac, 2004: Laboratory and in situ observation of deposition growth of frozen drops. J. Appl. Meteor., 43, 612-622, https://doi.org/ 10.1175/1520-0450(2004)043<0612:LAISOO>2.0.CO;2.

Larsen, M. L., A. B. Kostinski, and A. R. Jameson, 2014: Further evidence for superterminal raindrops. Geophys. Res. Lett., 41, 6914-6918, https://doi.org/10.1002/2014GL061397.

Libbrecht, K. G., and K. Lui, 2004: An investigation of laboratorygrown ice spikes. J. Glaciol., 50, 371-374, https://doi.org/ 10.3189/172756504781830015.

Löffler-Mang, M., and J. Joss, 2000: An optical disdrometer for measuring size and velocity of hydrometeors. J. Atmos. Oceanic Technol., 17, 130-139, https://doi.org/10.1175/15200426(2000)017<0130:AODFMS>2.0.CO;2.

Mason, B. J., and J. Maybank, 1960: The fragmentation and electrification of freezing water drops. Quart. J. Roy. Meteor. Soc., 86, 176-185, https://doi.org/10.1002/qj.49708636806.

Mitchell, D. L., 1996: Use of mass- and area-dimensional power laws for determining precipitation particle terminal velocities. J. Atmos. Sci., 53, 1710-1723, https://doi.org/10.1175/15200469(1996)053<1710:UOMAAD>2.0.CO;2.

Montero-Martínez, G., A. B. Kostinski, R. A. Shaw, and F. García-García, 2009: Do all raindrops fall at terminal speed? Geophys. Res. Lett., 36, L11818, https://doi.org/ 10.1029/2008GL037111.

NASA, 2011: DataFormat_parsivel. Accessed 15 February 2020, https://ghrc.nsstc.nasa.gov/pub/doc/gpmgv/parsivel/ DataFormat_parsivel_fieldCampaign.pdf.

NOAA, DOD, FAA, and U.S. Navy, 1998: Automated surface observing system user's guide. Accessed 18 February 2020, https://www.weather.gov/media/asos/aum-toc.pdf.

Pei, B., F. Y. Testik, and M. Gebremichael, 2014: Impacts of raindrop fall velocity and axis ratio errors on dual-polarization radar rainfall estimation. J. Hydrometeor., 15, 1849-1861, https://doi.org/10.1175/JHM-D-13-0201.1.

Phillips, V. T., A. Khain, N. Benmoshe, E. Ilotoviz, and A. Ryzhkov, 2015: Theory of time-dependent freezing. Part II: Scheme for freezing raindrops and simulations by a cloud model with spectral bin microphysics. J. Atmos. Sci., 72, 262-286, https://doi.org/10.1175/JAS-D-13-0376.1.

Pitter, R. L., and H. R. Pruppacher, 1973: A wind tunnel investigation of freezing of small water drops falling at terminal velocity in air. Quart. J. Roy. Meteor. Soc., 99, 540-550, https:// doi.org/10.1002/qj.49709942111.

Rauber, R. M., L. S. Olthoff, M. K. Ramamurthy, and K. E. Kunkel, 2000: The relative importance of warm rain and melting processes in freezing precipitation events. J. Appl. Meteor., 39, 1185-1195, https://doi.org/10.1175/1520-0450(2000)039<1185: TRIOWR $>2.0 . \mathrm{CO} ; 2$.

Raupach, T. H., and A. Berne, 2015: Correction of raindrop size distributions measured by Parsivel disdrometers, using a two-dimensional video disdrometer as a reference. Atmos. Meas. Tech., 8, 343-365, https://doi.org/10.5194/ amt-8-343-2015.

Sastry, S., 2005: Ins and outs of ice nucleation. Nature, 438, 746-747, https://doi.org/10.1038/438746a.

Schuster, S. S., R. J. Blong, and J. Mcaneney, 2006: Relationship between radar-derived hail kinetic energy and damage to insured buildings for severe hailstorms in eastern Australia. Atmos. Res., 81, 215-235, https://doi.org/10.1016/j.atmosres. 2005.12.003.

Stewart, R. E., and R. W. Crawford, 1995: Some characteristics of the precipitation formed within winter storms over eastern newfoundland. Atmos. Res., 36, 17-37, https://doi.org/10.1016/ 0169-8095(94)00004-W.

Symons, L., and A. Perry, 1997: Predicting road hazards caused by rain, freezing rain and wet surfaces and the role of weather radar. Meteor. Appl., 4, 17-21, https://doi.org/ 10.1017/S1350482797000339.

Takahashi, C., 1975: Deformations of frozen water drops and their frequencies. J. Meteor. Soc. Japan, 53, 402-411, https://doi.org/ 10.2151/jmsj1965.53.6_402.

_- 1976: Relation between the deformation and the crystalline nature of frozen water drops. J. Meteor. Soc. Japan, 54, 448-453, https://doi.org/10.2151/jmsj1965.54.6_448.

Tapiador, F. J., R. Checa, and M. de Castro, 2010: An experiment to measure the spatial variability of rain drop size distribution using sixteen laser disdrometers. Geophys. Res. Lett., 37, L16803, https://doi.org/10.1029/2010GL044120.

Testik, F. Y., and M. K. Rahman, 2016: High-speed optical disdrometer for rainfall microphysical observations. J. Atmos. Oceanic Technol., 33, 231-243, https://doi.org/10.1175/ JTECH-D-15-0098.1.

— , and — 2017: First in-situ observations of binary raindrop collisions. Geophys. Res. Lett., 44, 1175-1181, https://doi.org/ 10.1002/2017GL072516.

__ A. P. Barros, and L. F. Bliven, 2006: Field observations of multimode raindrop oscillations by high-speed imaging. J. Atmos. Sci., 63, 2663-2668, https://doi.org/10.1175/ JAS3773.1.

Thériault, J. M., and R. E. Stewart, 2010: A parameterization of the micro-physical processes forming many types of winter precipitation. J. Atmos. Sci., 67, 1492-1508, https://doi.org/ 10.1175/2009JAS3224.1.

,,-- J. A. Milbrandt, and M. K. Yau, 2006: On the simulation of winter precipitation types. J. Geophys. Res., 111, D18202, https://doi.org/10.1029/2005JD006665.

,- , and W. Henson, 2010: On the dependence of winter precipitation types on temperature, precipitation rate and associated features. J. Appl. Meteor. Climatol., 49, 1429-1442, https://doi.org/10.1175/2010JAMC2321.1. 
Thurai, M., V. N. Bringi, W. A. Petersen, and P. N. Gatlin, 2013: Drop shapes and fall speeds in rain: Two contrasting examples. J. Appl. Meteor. Climatol., 52, 2567-2581, https://doi.org/ 10.1175/JAMC-D-12-085.1.

Tokay, A., D. B. Wolff, and W. A. Petersen, 2014: Evaluation of the new version of the laser-optical disdrometer, OTT Parsivel2. J. Atmos. Oceanic Technol., 31, 1276-1288, https://doi.org/ 10.1175/JTECH-D-13-00174.1.
Visagie, P., 1969: Pressures inside freezing water drops. J. Glaciol., 8, 301-309, https://doi.org/10.1017/S0022143000031270.

Wildeman, S., S. Sterl, C. Sun, and D. Lohse, 2017: Fast dynamics of water droplets freezing from the outside in. Phys. Rev. Lett., 118, 084101, https://doi.org/10.1103/PhysRevLett.118.084101.

Zerr, R. J., 1997: Freezing rain: An observational and theoretical study. J. Appl. Meteor., 36,1647-1661, https://doi.org/10.1175/ 1520-0450(1997)036<1647:FRAOAT >2.0.CO;2. 